\title{
The BepiColombo-Mio Magnetometer en Route to Mercury
}

\author{
W. Baumjohann ${ }^{1}$ - A. Matsuoka ${ }^{2}$ Y. Narita ${ }^{1}$. W. Magnes $^{1}$ - D. Heyner ${ }^{3}$. \\ K.-H. Glassmeier ${ }^{3,4}$ - R. Nakamura ${ }^{1}$ D. Fischer $^{1}$ - F. Plaschke ${ }^{1} \cdot$ M. Volwerk ${ }^{1}$. \\ T.L. Zhang' - H.-U. Auster ${ }^{3}$ - I. Richter ${ }^{3}$ - A. Balogh ${ }^{5}$ - C.M. Carr ${ }^{5}$ - M. Dougherty ${ }^{5}$. \\ T.S. Horbury ${ }^{5}$ - H. Tsunakawa ${ }^{6}$ - M. Matsushima ${ }^{7}$ - M. Shinohara ${ }^{8}$ - H. Shibuya9 . $^{\circ}$ \\ T. Nakagawa ${ }^{10} \cdot$ M. Hoshino ${ }^{11}$ - Y. Tanaka ${ }^{12}$ - B.J. Anderson ${ }^{13}$ - C.T. Russell ${ }^{14}$. \\ U. Motschmann ${ }^{15,16} \cdot$ F. Takahashi ${ }^{17}$ - A. Fujimoto ${ }^{18}$
}

Received: 1 December 2019 / Accepted: 3 October 2020 / Published online: 28 October 2020

(C) The Author(s) 2020

\begin{abstract}
The fluxgate magnetometer MGF on board the Mio spacecraft of the BepiColombo mission is introduced with its science targets, instrument design, calibration report, and scientific expectations. The MGF instrument consists of two tri-axial fluxgate magnetometers. Both sensors are mounted on a $4.8-\mathrm{m}$ long mast to measure the magnetic field around Mercury at distances from near surface (initial peri-center altitude is $590 \mathrm{~km}$ ) to 6
\end{abstract}

The BepiColombo mission to Mercury

Edited by Johannes Benkhoff, Go Murakami and Ayako Matsuoka

\section{Y. Narita}

1 Space Research Institute, Austrian Academy of Sciences, 8042 Graz, Austria

2 World Data Center for Geomagnetism, Graduate School of Science, Kyoto University, Kyoto 606-8502, Japan

3 Institut für Geophysik und extraterrestrische Physik, Technische Universität Braunschweig, 38106 Braunschweig, Germany

4 Max-Planck-Institut für Sonnensystemforschung, 37077 Göttingen, Germany

5 Blackett Laboratory, Imperial College, London SW72AZ, UK

6 Institute of Space and Astronautical Science, Japan Aerospace Exploration Agency, Sagamihara, Kanagawa, 229-8510, Japan

7 Department of Earth and Planetary Sciences, Tokyo Institute of Technology, Meguro, Tokyo 152-8551, Japan

8 National Institute of Technology, Kagoshima College, Kirishima, Kagoshima 899-5193, Japan

9 Department of Earth Sciences, Kumamoto University, Kurokami, Kumamoto 860-8555, Japan

10 Department of Information and Communication Engineering, Tohoku Institute of Technology, Sendai, Miyagi 982-8577, Japan

11 Department of Earth and Planetary Science, University of Tokyo, Bunkyo, Tokyo 113-0033, Japan

12 National Institute of Polar Research, Tachikawa, Tokyo 190-8518, Japan

13 Applied Physics Laboratory, Johns Hopkins University, Laurel, MD 20723, USA 
planetary radii $(11640 \mathrm{~km})$. The two sensors of MGF are operated in a fully redundant way, each with its own electronics, data processing and power supply units. The MGF instrument samples the magnetic field at a rate of up to $128 \mathrm{~Hz}$ to reveal rapidly-evolving magnetospheric dynamics, among them magnetic reconnection causing substorm-like disturbances, field-aligned currents, and ultra-low-frequency waves. The high time resolution of MGF is also helpful to study solar wind processes (through measurements of the interplanetary magnetic field) in the inner heliosphere. The MGF instrument firmly corroborates measurements of its companion, the MPO magnetometer, by performing multi-point observations to determine the planetary internal field at higher multi-pole orders and to separate temporal fluctuations from spatial variations.

Keywords Magnetic field $\cdot$ Mercury $\cdot$ Magnetosphere $\cdot$ Inner heliosphere

\section{Introduction}

Understanding the magnetic field environment around Mercury is one of the primary science targets in the BepiColombo mission (Benkhoff et al. 2010). From a space plasma point of view, Mercury is distinct among the solar system's planets in that

1. the planet possesses an intrinsic magnetic field and magnetosphere even though the planet itself is rather small (a radius of about $2440 \mathrm{~km}$ ) and rotating slowly (cf., other "terrestrial" bodies such as Venus, Mars, and Earth's Moon do not have an intrinsic field),

2. the size of magnetosphere is very small and comparable to the gyro-radius of heavy ions $\left(\mathrm{Na}^{+}\right.$, for example, has a gyro-radius of about $\left.1000 \mathrm{~km}\right)$, making the magnetosphere respond quickly to the changes in the solar wind condition such as flow speed, density variation, magnetic field direction with a characteristic time scale of the magnetosphere about 1-2 minutes (Balogh 1997; Baumjohann et al. 2006; Slavin et al. 2009)),

3. the lack of an ionosphere makes the magnetospheric dynamics (through the electric current configuration) different from Earth's magnetosphere with its ionosphere (Glassmeier 1997; Slavin et al. 1997).

Mercury's planetary magnetic field was discovered by Mariner 10's flybys in 1974 and 1975 (Ness et al. 1974, 1975). The discovery was the most surprising result of the mission because the thermal condition, the rotation rate, and the presumed core state (believed to be a solid iron core) seemingly excluded the possibility of a dynamo mechanism in operation. Already Mariner 10 observed a variety of magnetospheric structures and processes such as a dipolar-like intrinsic field, magnetopause, magnetotail, substorm-like disturbances (Siscoe

14 Institute of Geophysics and Planetary Physics, University of California, Los Angeles, CA 90095, USA

15 Institut für Theoretische Physik, Technische Universität Braunschweig, 38106 Braunschweig, Germany

16 DLR Institute of Planetary Research, 12489 Berlin, Germany

17 Department of Earth and Planetary Sciences, Faculty of Science, Kyushu University, Fukuoka 819-0395, Japan

18 School of Computer Science and Systems Engineering, Kyushu Institute of Technology, Kawazu, Fukuoka 820-8502, Japan 
et al. 1975), and ultra-low-frequency (ULF) waves (Russell 1989). Various currents flowing in Mercury's magnetosphere system were identified such as magnetopause current, magnetotail current, field-aligned currents, reconfiguration currents, and induced currents within the planet (Glassmeier 2000).

The MESSENGER mission (Solomon et al. 2007), launched in 2004 and orbiting Mercury from 2011 to 2015, improved our understanding of Mercury's magnetosphere after Mariner 10 significantly. The surface equatorial field is estimated at about 250 to $290 \mathrm{nT}$ with a dipole field contribution at surface level in the range from 180 to $220 \mathrm{nT}$. The magnetic equator in the tail is shifted northward, giving an offset dipole magnetosphere as the lowest-order picture (Anderson et al. 2011, 2012). From a dynamo theoretical point of view, the northward offset of the magnetic equator implies that higher-order terms, in particular the quadrupole field, play a more important role than in the other magnetospheres like at Earth, Jupiter, and Saturn (the quadrupole term also plays an important role at both Uranus and Neptune). For a more comprehensive review of Mercury's magnetic field see, e.g., Anderson et al. (2010) and Wicht and Heyner (2014).

The MESSENGER observations revealed the magnetospheric structure and processes in more detail. The dayside magnetopause is located at a distance of about $1.5 R_{\mathrm{M}}$ from the center of the planet (Johnson et al. 2012), and can reach even $1.1 R_{\mathrm{M}}$ under a high dynamic pressure in the solar wind (Slavin et al. 2014). The magnetotail has a radius of about $3 R_{\mathrm{M}}$ from the Mercury-Sun line when represented as a cylinder (Johnson et al. 2012). The magnetopause shape is asymmetric (or non-axially-symmetric) between the north-south and the dawn-dusk sections (Zhong et al. 2015). Field-aligned currents are either entirely closed within the magnetospheric plasma (Glassmeier et al. 2010), or they are connecting the magnetosphere and the planet by a surface or sub-surface currents (Anderson et al. 2014). X-ray aurora detected at Mercury's surface is also associated with the field-aligned currents (Lindsay et al. 2016).

Mercury's magnetosphere is highly time dependent. Magnetopause reconnection is considered as the dominant driver of magnetospheric dynamics. Various phenomena such as a shower of flux transfer events (Slavin et al. 2012), dipolarization fronts (Sundberg et al. 2012a) and field-aligned currents (Slavin et al. 1997; Anderson et al. 2014). presumably originate in the reconnection process. The interplay between reconnection at the magnetopause and induction in the core was assessed by Heyner et al. (2016). In addition, the bow shock evolves by re-forming itself in a cyclic way (Slavin et al. 2009b; Sundberg et al. 2013). There are various kinds of waves and transient phenomena. Wave modes include Kelvin-Helmholtz vortices (Boardsen et al. 2010; Liljeblad et al. 2014, 2016; Gershman et al. 2015; Sundberg et al. 2011, 2013), ion cyclotron waves in the magnetosheath (Sundberg et al. 2015), ion Bernstein waves (Boardsen et al. 2012), and polarized ULF waves with an indication of field-line resonances (James et al. 2016). Magnetic field fluctuations may develop into turbulence in various regions (Uritsky et al. 2011).

The BepiColombo Mio magnetometer MGF aims to study the Hermean magnetosphere and the interplanetary magnetic field in the inner heliosphere more comprehensively with the spin-stabilized spacecraft in its highly elliptical orbit around Mercury. The semi-major axis of spacecraft orbit lies nearly in Mercury's orbital plane. The spacecraft orbital plane rotates due to the planet orbital motion (see Murakami et al. 2020), hence the Mio magnetometer MGF performs magnetic field observations in various regions of the Hermean magnetosphere.

The orbit peri-center is about $590 \mathrm{~km}$ and the apo-center about $11640 \mathrm{~km}$ (about 6 planetary radii), initially. The Mio magnetometer will construct a more complete picture of the Hermean magnetosphere after the Mariner 10 and MESSENGER missions. 
The Mio magnetometer samples the magnetic field at sampling rates of up to $128 \mathrm{~Hz}$ to ensure proper measurements in the highly dynamic magnetosphere of Mercury (the cadence of measurements needs to be high enough to resolve physical processes in the magnetosphere), and will also corroborate the study by its companion magnetometer on board Mercury Planetary Orbiter (MPO) (Glassmeier et al. 2010; Heyner et al. 2020) to perform multi-point observations around Mercury for various purposes, e.g., identification of the internal and external fields, separation of temporal fluctuations from spatial variations, multipole expansion of the planetary field, monitoring the solar wind by the Mio spacecraft while measuring the magnetosphere by the MPO spacecraft.

\section{Science targets of Mio magnetometer}

\subsection{Overview}

Science targets of Mio magnetometer include various magnetospheric processes (such as magnetic reconnection, field-aligned currents, and ultra-low-frequency waves), physics of bow shock and magnetosheath around Mercury, and the magnetic field properties in the inner heliosphere. The Mio magnetometer also supports the MPO magnetometer in characterizing the planetary internal magnetic field. The small magnetospheric scale and the lack of an ionosphere lead us to raise the following questions about the mechanisms driving substorm-like disturbances in the magnetosphere: Under what condition does the magnetic reconnection set on? How large is the reconnection rate (which is the amount of reconnecting magnetic flux or equivalently the strength of the convective electric field associated with inflow)? How does the current system close along the magnetic field lines connecting the planetary surface with the distant tail? What kinds of waves are there in Mercury's magnetosphere? How are the energy and momentum transferred by means of the waves? With the highly elliptic orbit of the Mio spacecraft, MGF can finally study magnetic reconnection and associated field-aligned currents in the magnetotail of Mercury. Studying Mercury's magnetosphere is of great interest and importance for its uniqueness such as the small spatial size comparable to the gyro-radius of heavy ions, quick response to changes in the solar wind, significance of plasma kinetic effects, lack of an electrically-conducting ionosphere, and its close distance to the Sun. The MGF will serve as the key instrument to reveal physical mechanisms operating in the Hermean magnetosphere, sustaining its structure, and solar wind phenomena in the inner heliosphere. Table 1 summarizes the science targets and corresponding instrument modes of Mio magnetometer.

\subsection{Magnetic reconnection}

Magnetic reconnection is the key process in driving magnetospheric dynamics and substorm-like disturbances at Mercury, first discovered in the Mariner-10 data (Siscoe et al. 1975). Substorms are recognized in Earth's magnetosphere as a sudden disturbance in the magnetospheric plasma and magnetic field (e.g., Akasofu 1964; Kan et al. 1991; Angelopoulos et al. 2008; Kepko et al. 2015). Magnetic reconnection at the dayside magnetopause rips off the magnetic field lines of the Earth and the solar wind flow takes the field lines to the magnetotail. The energy accumulated in the magnetotail is released in an explosive fashion, and again, magnetic reconnection is the most likely process that initiates a sudden disturbance in the magnetotail. Magnetic field behavior in collisionless reconnection depends on the spatial scales: Frozen-in magnetic field around the diffusion region in the fluid picture 
Table 1 Mio magnetometer science targets

\begin{tabular}{|c|c|c|c|}
\hline Region & Science target & Remarks & Instrument mode \\
\hline \multirow[t]{3}{*}{$\begin{array}{l}\text { Hermean } \\
\text { magnetosphere }\end{array}$} & Magnetic reconnection & $\begin{array}{l}\text { - Reconnection rate } \\
\text { - Substorm activities }\end{array}$ & $\mathrm{H}$ mode $(128 \mathrm{~Hz})$ \\
\hline & $\begin{array}{l}\text { Field-aligned currents } \\
\text { (FAC) }\end{array}$ & $\begin{array}{l}\text { - Global structure of currents } \\
\text { - Energy transfer by currents }\end{array}$ & $\mathrm{H}$ mode $(128 \mathrm{~Hz})$ \\
\hline & $\begin{array}{l}\text { Ultra-low-frequency } \\
\text { (ULF) waves }\end{array}$ & $\begin{array}{l}\text { - Kinetic effects } \\
\text { - Energy transfer by waves } \\
\text { - Waves associated with heavy ions }\end{array}$ & M1 mode $(8 \mathrm{~Hz})$ \\
\hline \multirow[t]{2}{*}{$\begin{array}{l}\text { Inner } \\
\text { heliosphere }\end{array}$} & Solar wind & $\begin{array}{l}\text { - Heating mechanism } \\
\text { - Turbulent fluctuations }\end{array}$ & $\mathrm{H}$ mode $(128 \mathrm{~Hz})$ \\
\hline & Shocks and transients & $\begin{array}{l}\text { - Hermean bow shock } \\
\text { - Interplanetary shocks } \\
\text { - Coronal mass ejections } \\
\text { - Co-rotating interaction regions }\end{array}$ & $\mathrm{H}$ mode $(128 \mathrm{~Hz})$ \\
\hline $\begin{array}{l}\text { Mercury planetary } \\
\text { magnetic field } \\
\text { (together with } \\
\text { MPO-MAG) }\end{array}$ & Internal field & $\begin{array}{l}\text { - Separation from external field } \\
\text { - Multi-pole expansion }\end{array}$ & $\mathrm{L}$ mode (1/spin) \\
\hline
\end{tabular}

Note: M2 mode is dedicated to the calibration purpose to separate the measurement data from the spacecraftgenerated magnetic field. See Table 4 for the mode definition

(on scales of about $1000 \mathrm{~km}$ or larger), ion demagnetization and Hall effect in the ion diffusion region (on scales of about $100 \mathrm{~km}$ ), and electron demagnetization and electron-kinetic effects such as gradient of electron stress due to non-gyrotropic motions in the electron diffusion region (on scales of about a few $\mathrm{km}$ ).

It is questionable if the picture of magnetic reconnection in Earth's magnetosphere is valid in Mercury's magnetosphere. The fluid picture of plasma fails at Mercury because the size of the magnetosphere is only of the same order as the ion gyro-radius (for sodium ions, in particular). Time scales of reconnection and substorm-like disturbances are much shorter at Mercury. One may naively estimate the time scale of substorm-like disturbance at Mercury as the ratio of characteristic magnetotail lengths between Mercury and the Earth, which is about $15 \%$ (when using 20 Earth radii and 10 Mercury radii), which implies a substorm-like disturbance within about 6 minutes at Mercury (cf. time scale is about 40 minutes in Earth's magnetosphere).

The MESSENGER spacecraft observed a number of flux transfer events presumably driven by magnetic reconnection (Slavin et al. 2012). Mercury's magnetosphere can be exposed to extreme solar wind conditions (Slavin et al. 2014; Exner et al. 2018). Physical processes associated with the substorms will be studied in detail, such as dipolarization of the magnetosphere (Sundberg et al. 2012a), particle acceleration (Delcourt et al. 2010; Zelenyi et al. 2007), and the X-ray aurora emission (Lindsay et al. 2016).

The high sampling rate of MGF and the spacecraft in the magnetotail are ideally suited to collect a number of reconnecting magnetic field events, plasmoid formation, and dipo- 
larization front propagation directly in the magnetotail. Conditions, occurrence frequency, reconnection rate, impacts on the magnetosphere, and details mechanisms of magnetic reconnection in the Hermean magnetosphere will be revealed with the help of MGF.

\subsection{Field-aligned currents}

Field-aligned currents play an important role in the transfer of energy and momentum between the distant tail and the ionosphere, and are closely related to substorm-like disturbances of the magnetosphere. If the planet is surrounded by both an ionosphere and a magnetosphere, the field-aligned currents couple these two plasma domains tightly. The fieldaligned currents transmit the disturbance in the magnetosphere down to the ionosphere and are closed on the ionospheric level by Hall and Pedersen currents crossing the magnetic field lines.

The pioneering observational study by Iijima and Potemra (1976) showed the presence of two distinct belts upward and downward currents in the polar ionosphere of the Earth. In the northern hemisphere, Region-I currents flow from the magnetosphere onto the ionosphere in the poleward morning sector, and vice versa in the poleward evening sector. Region-II currents are located equatorward of the Region-I currents, and flow in the opposite sense of polarity to the Region-I currents. The field-aligned currents are a part of a closed circuit loop in the magnetosphere-ionosphere system. The currents are closed on the ionospheric level by Hall and Pedersen currents. Field-aligned currents appear in various forms, e.g., substorm current wedge (Clauer and McPherron 1974; Ritter and Lühr 2008; Kepko et al. 2015), currents flowing during times of northward interplanetary magnetic field (Zanetti et al. 1984; Vennerstrøm et al. 2002), and cusp currents (Cowley 2000).

Field-aligned currents are carried not only by charged particles streaming nearly along the magnetic field line (within the loss cone) but also by Alfvén waves propagating along the field line. In the wave picture, the field-aligned currents are determined by the change in the inertial and diamagnetic currents associated with the inhomogeneous and curved magnetic field lines (Southwood and Kivelson 1991; Itonaga et al. 2000).

Mercury's magnetospheric system is unique in lacking an ionosphere. How is the global reconfiguration of the magnetosphere organized without closing the field-aligned currents on the ionospheric level? While the existence of field-aligned currents is indicated by the Mariner-10 and MESSENGER magnetic field observations (Slavin et al. 1997; Anderson et al. 2014), there are different possibilities of the current closure, e.g., closure in the magnetosphere (above surface) by the diamagnetic drift or plasma instabilities, surface closure, sub-surface closure by connecting to the planetary core. MGF will detect and track the field-aligned currents from distant tail region (up to $6 R_{\mathrm{M}}$ ) down to the near-surface region. Although very weak, the exo-ionosphere may intercept some of the field-aligned currents as shown by Exner et al. (2020).

\subsection{ULF waves}

The MGF magnetometer measures the magnetic field at a sufficiently close distance to the surface near the peri-center (down to an altitude of $590 \mathrm{~km}$ ). Field-line resonance and eigenmode oscillations are present in the planetary field of Mercury (Russell 1989; Othmer et al. 1999; Kim et al. 2013), and will be studied by MGF in detail. Due to the lack of an ionosphere, the mechanism of field-line resonance such as the reflection and bouncing motion of waves (e.g., Alfvén waves) between the two polar regions along the field line is expected 
to be different from that in the Earth's magnetosphere (Glassmeier et al. 2003, 2004; Glassmeier and Espley 2006; James et al. 2016). The small spatial scale of the magnetosphere may impose that the wave motion is closely coupled to kinetic processes (e.g., ion inertial effect, Hall electric field, non-Maxwellian velocity distributions, wave-particle interactions). Sodium ions may play an important role in the wave dynamics as well (Boardsen and Slavin 2007). Based on the MESSENGER observations of waves and turbulence (Uritsky et al. 2011; Boardsen et al. 2012), the MGF magnetometer will make a full survey of the waves and turbulent fields at various radial distances from the planet and in both hemispheres.

Also, the Mio spacecraft will encounter the magnetosphere flank region between Mercury's apohelion and perihelion phases, and the MGF magnetometer can make a systematic study of the flank-side magnetopause (e.g., structure and dynamics) after the MESSENGER observations (DiBraccio et al. 2013). The Kelvin-Helmholtz instability sets on at the Hermean magnetopause (Boardsen et al. 2010; Sundberg et al. 2011, 2012b; Paral and Rankin 2013; Liljeblad et al. 2014, 2016; Gershman et al. 2015) but the growth of the KelvinHelmholtz vortices is expected to be different between the dawn and dusk sides (Glassmeier and Espley 2006; Paral and Rankin 2013). The Kelvin-Helmholtz-type vortex mechanism, propagation and evolution, and spatial distribution are studied in detail by the MGF magnetometer.

Isolated magnetic field structures (e.g., Karlsson et al. 2016) are found in the solar wind and planetary magnetosheaths. These structures are assumed to be the final stage of the mirror mode when the plasma is stabilized by a diffusion process. The BepiColombo constellation allows simultaneous measurements of the isolated magnetic field structures around Mercury. Both the solar wind conditions and the local plasma parameters can be obtained to improve our knowledge about properties and conditions of the local structures.

\subsection{Bow shock and magnetosheath}

The Mio spacecraft often crosses the bow shock, magnetosheath, and magnetopause near Mercury's perihelion. Detailed bow shock structures are studied in view of the magnetic field dependence (quasi-parallel and quasi-perpendicular shocks), plasma beta dependence, and wave excitations. The solar wind and the bow shock measurements are performed using the M1 mode (nominal) and the event-triggered $\mathrm{H}$ mode. The interplanetary magnetic field is oriented in a more radial direction from the Sun near Mercury's perihelion than that observed around the Earth orbit. Therefore, the shock-upstream disturbances such as back-streaming ions and the associated waves (Fairfield and Behannon 1976) are considered to reach far upstream of the shock. The high sampling rate of the MGF magnetometer is ideal to study the shock transition and upstream waves (wave phenomena at the shock transition layer and in the shock-upstream region have a shorter time scale due to a higher Alfvén speed than that of the Earth bow shock). Bow shock and magnetopause locations can be tracked by the MGF magnetometer in the night-side flank region, which will be an important ingredient to the magnetospheric model and consequently to the separation of the internal magnetic field from the external field.

\subsection{Solar wind}

The Mio magnetometer also serves as a monitor of the interplanetary magnetic field at Mercury's orbit when the spacecraft orbit peri-center (located at a distance of about $6 R_{\mathrm{M}}$ from the planet) comes to the dayside corresponding to Mercury's orbital phase near perihelion. While the solar wind speed at Mercury's orbit (at about $0.3 \mathrm{AU}$ ) is expected to be nearly the 
same as that at Earth's orbit, the interplanetary magnetic field at Mercury's orbit is stronger and more radial than that at Earth's orbit. Solar wind processes such as flow acceleration, local heating in interplanetary space, Hermean bow shock, and development into turbulence will be studied by the Mio magnetometer. Also, transient phenomena such as interplanetary shocks. coronal mass ejections, co-rotating interaction regions, and sector boundary crossings will be studied.

The Mio spacecraft spends a longer time in the solar wind near Mercury's perihelion when the spacecraft apo-center is located on the dayside of the planet. The MGF magnetometer will study large-scale magnetic field structures (Suzuki 2002; Lhotka and Narita 2019) and plasma turbulence in the inner heliosphere (Perri et al. 2010, 2012), for different solar wind types (e.g., fast and slow winds). Fluctuation properties may closely be associated with the origin of fast and slow solar winds (Hollweg and Isenberg 2002). Transient events such coronal mass ejections and co-rotating interaction regions are measured at a distance of about $0.3 \mathrm{AU}$, providing the data for the magnetic structures in the early evolution phase in interplanetary space. Also, the Mio spacecraft serves as a solar wind monitor to the MPO observations in the inner magnetosphere. Such a coordinated study using two spacecraft reveals the dependence of Mercury's magnetosphere and its dynamics on the solar wind condition after the MESSENGER observations (Slavin et al. 2009b). The dayside magnetosphere may disappear (Slavin et al. 2019) during intervals of extremely high dynamic pressure in the solar wind such as during coronal mass ejections (compressed magnetosphere) or enhanced dayside magnetic reconnection (magnetic field erosion). The MGF magnetometer serves ideally as the solar wind monitor while the MPO magnetometer watches the magnetospheric response under the extreme solar wind conditions.

The interplanetary shocks may have a larger variability and the Alfvén Mach number can reach about 40 . The electron surfing acceleration by electrostatic waves at the shock operates at the Alfvén Mach number of 43 to 75 (Hoshino and Shimada 2002), which fills the gap between the shocks in the solar system (with lower Mach numbers of the order 10) and that in the astrophysical systems (with higher Mach numbers of the order of 100 to 1000).

\subsection{Planetary field}

Mercury's magnetosphere is so small that the currents flowing in the magnetosphere can influence the near-surface field (and even interior of the planet) as an external field (e.g., Glassmeier et al. 2007; Heyner et al. 2011). Such a coupling between the magentosphere and the dynamo is unique in solar system science and makes Mercury's magnetosphere a challenging and interesting subject. The Mio magnetometer collaborates with the MPO magnetometer in separating the internal field from the external field and performing the multi-pole expansion into spherical harmonics. The mechanism of the northward-shifted magnetic equator will be clarified, e.g., if the equator shift is of dipole field origin or if the quadrupole has a significant contribution.

Various kinds of coordinated studies are possible together with the MPO magnetometer. Moreover, both spacecraft (Mio and MPO) have nearly symmetric orbits between the northern and southern hemispheres, ideal to separate the magnetic field of internal origin from that of external origin and to perform a spherical harmonic analysis on the planetary internal field. The internal sources include the magnetic field generated by the dynamo mechanism (Wicht and Heyner 2014), the remanent crustal field (Johnson et al. 2015; Oliveira et al. 2019), and time-varying induction field in response to changes in the solar wind and magnetospheric conditions (Grosser et al. 2004; Johnson et al. 2016). The external fields originate in the currents flowing in the magnetosphere, e.g., magnetopause current on the 
Fig. 1 MGF sensor locations on the Mio spacecraft mast

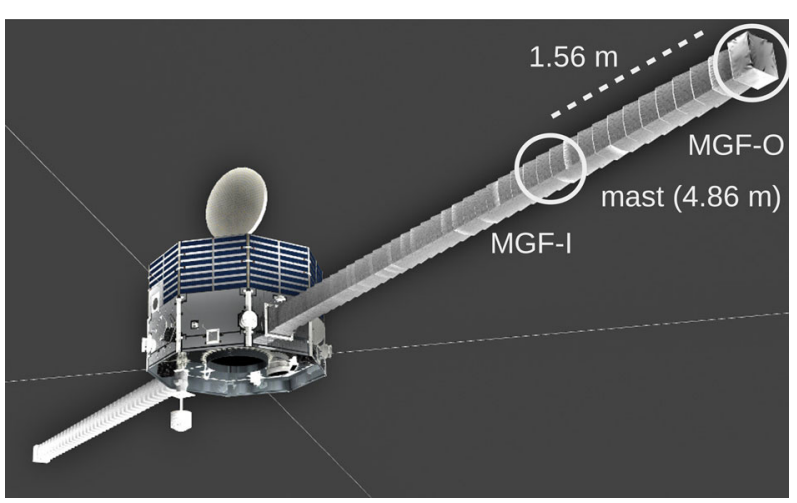

dayside and in the tail, plasma sheet current, field-aligned current, and possibly a partial ring current (Müller et al. 2012; Korth et al. 2015). The MGF magnetometer strongly assist the MPO magnetometer to properly estimate the higher-order terms of the planetary field (quadrupole, octupole, and higher) and will find a solution for the northward offset of the magnetic equator.

\section{Instrument design}

\subsection{Overview}

The Mio magnetometer MGF is a set of two tri-axial fluxgate magnetometers. The outboard magnetometer is referred to as MGF-O, and its sensor is located at the tip of 4.86-m long mast, which is dedicated to the fluxgate sensors. (Fig. 1). The inboard magnetometer is referred to as MGF-I and the sensor is mounted on the same mast as that for MGF-O with a distance of $1.56 \mathrm{~m}$ from the mast tip. Both sensors are connected to the respective electronics with a sensor harness of several meters. The two sensors on the same mast form a geometry for gradiometer measurements along the mast. This gradiometer with a dual magnetometer can identify the spacecraft-generated field (from magnetic material or current circuit in the spacecraft body) which is required for data correction and calibration purposes (Ness et al. 1971; Hedgecock 1975; Georgescu et al. 2008).

The two magnetometers, MGF-O and MGF-I, are independently operated by the respective digital processing units (DPU) and power supply units (PSU) to minimize the risk of a total loss of the low-frequency magnetic field measurements on board the Mio spacecraft. The Mio magnetometer sensors for MGF-O and MGF-I are displayed in Fig. 2 panels (a) and (b). The block diagram of MGF is displayed in Fig. 2, panel (c). The digital data from MGF-O are processed by the data processor DPU-1, which is mainly responsible for the particle instrument suite, while the data from MGF-I are processed by DPU-2, which handles the field instrument suite. Mass, electric power, dynamic range, resolution, sampling rate, frequency range, and noise level are summarized in Table 2. Short introductions to the MGF-O and MGF-I designs are provided in Sects. 3.2 and 3.3, respectively. A more detailed description of the Mio MGF design is given in the earlier instrument introduction by Baumjohann et al. (2010).

Fluxgate sensors in general consist of a set of coil systems with a highly permeable, ferromagnetic core (Primdahl 1979). Three coils are used per axis. First, an excitation coil 
Fig. 2 Outboard sensor (panel a), inboard sensor (panel b), and block diagram of MGF (panel c) (a) MGF-O sensor

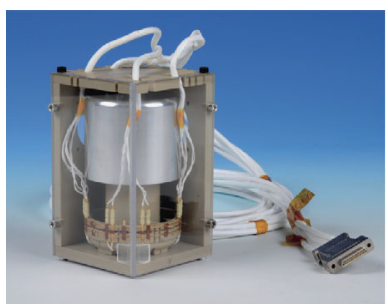

(b) MGF-I sensor

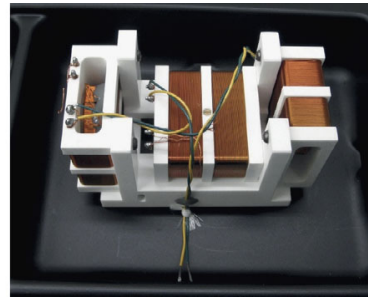

(c) Logical diagram

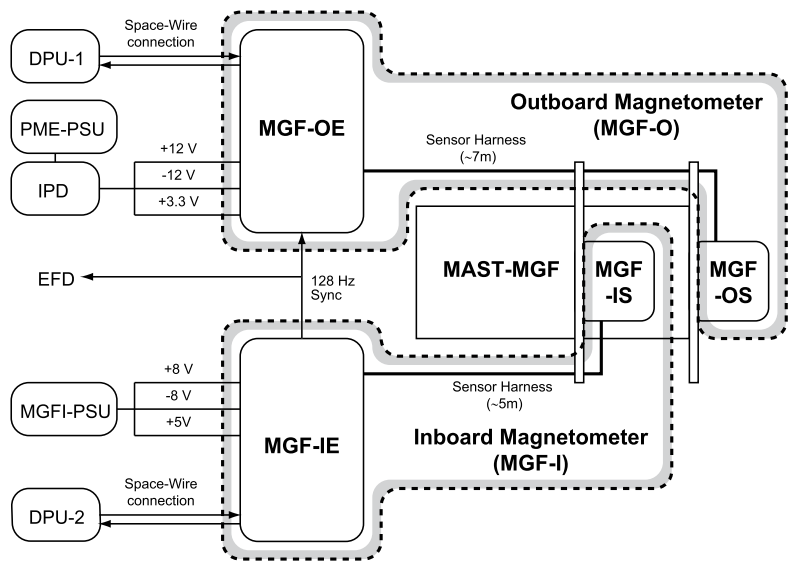

(driving coil) wound around the core (often using a ring-core) excites the ferromagnetic material large-amplitude (over-saturating), high-frequency (typically in the kHz range) currents. Second, a pick-up coil wound around the same coil detects a waveform in magnetic induction distorted by the saturation of the ferromagnetic core with an asymmetry imposed by the background magnetic flux. The amplitude of the second harmonic of the excitation field is proportional to the external magnetic flux, and is extracted by the read-out electronics. Use of ring-cores is advantageous in that the odd harmonics and the offset parameter can be adjusted to a minimum by rotating the ring-core. Finally, a feedback coil generates a compensation magnetic field and cancels the external field such that the sensor system has a broad dynamical range of the magnetic field (covering many orders of magnitude in field strength) with high linearity and stability. In some applications, the pickup and feedback coils are combined, which is one possibility for reducing mass and complexity. Each single-axis coil system measures a component of the magnetic field, thus three coil systems are used to measure three components of the magnetic field. MGF-O and MGF-I differ from each other in the coil system and the operation style: a mixed signal (analogue and digital) near sensor regulation loop for MGF-O and an analogue signal near sensor regulation loop for MGF-I.

\subsection{Outboard magnetometer MGF-O}

The outboard magnetometer MGF-O is constructed after the digital fluxgate magnetometer design (Auster et al. 1995) which has successfully been applied to Rosetta lander (Auster 
Table 2 Mio magnetometer characteristics

\begin{tabular}{lll}
\hline Parameter & Unit & Value \\
\hline Mass & MGF-O & $288 \mathrm{~g}$ \\
MGF-I & $414 \mathrm{~g}$ \\
& Total & $766 \mathrm{~g}$ \\
MGF-O & $1.65 \mathrm{~W}$ \\
Power & MGF-I & $2.17 \mathrm{~W}$ \\
& Total & $4.43 \mathrm{~W}$ \\
Dynamic range & $\pm 2048 \mathrm{nT}$ \\
Resolution & & $3.9 \mathrm{pT}$ at $20-$ bit resolution \\
Vector rate & max. $128 \mathrm{~Hz}$ \\
& max. $128 \mathrm{~Hz}$ \\
Frequency range & From $\mathrm{DC}$ to about $60 \mathrm{~Hz}$ in wave analyses \\
Noise level & below $10 \mathrm{pT} / \mathrm{Hz}$ (1/2 at $1 \mathrm{~Hz}$ \\
& below $40 \mathrm{pT}$ root-mean-square in the range $0.1-10 \mathrm{~Hz}$ \\
\hline
\end{tabular}

et al. 2007), Venus Express (Zhang et al. 2006, 2007), and THEMIS (Auster et al. 2008). MGF-O was designed and manufactured in a close cooperation between the Space Research Institute, Austrian Academy of Sciences (IWF), Austria, and the Institut für Geophysik und extraterrestrische Physik at the Technische Universität Braunschweig, Germany.

The MGF-O sensor consists of a set of two ring-cores, coil systems, and a stand-off made from polymer for the thermal decoupling from the mast interface. Two crossed ringcores (used for three components) with diameters of $13 \mathrm{~mm}$ and $18 \mathrm{~mm}$, respectively, are integrated within a separate pick-up and compensation coil system.

The ring-cores are integrated into two three-dimensional coil systems. The inner coil system is used for picking up the second harmonics of the driving frequency at which the signal amplitude is proportional to the external magnetic field. The outer coil system is constructed in a Helmholtz configuration and is used as a compensation system to cancel out the field at the ring-core position. The pick-up coil system is located at the closest possible position to the ring-cores in order to enhance the signal to noise ratio. All coils are made from bondcoated copper wire by minimizing the additional mechanical supports and avoiding the use of material with different thermal expansion coefficients with a clear focus on reducing sensor mass. The sensor system is covered by a cylindrical envelope with a height of $91 \mathrm{~mm}$ and a diameter of $55 \mathrm{~mm}$. The sensor core has a weight of less than $40 \mathrm{~g}$ (not including harness, mounting elements, protection cap, and thermal hardware).

The electronics has a minimal set of components. It conducts digitalization of the output from the pick-up coils immediately after the input amplifiers at a sampling frequency four times higher than the driving frequency. Functions of the analogue signal processing are replaced by algorithms implemented in a field programmable gate array (FPGA) in order to reduce temperature drifts and to minimize inter-axes interference. The amplitude response and noise profile of the MGF-O sensor are displayed as a function of frequencies in Fig. 3. The amplitude response is nearly unity up to a frequency of about $10 \mathrm{~Hz}$, and becomes then gradually diminished from 10 to $100 \mathrm{~Hz}$ and beyond. The noise profile represented by the 
Fig. 3 Amplitude response and noise profile (spectral amplitude) of the MGF-O sensor as a function of frequencies from the measurement in a shielded environment on ground
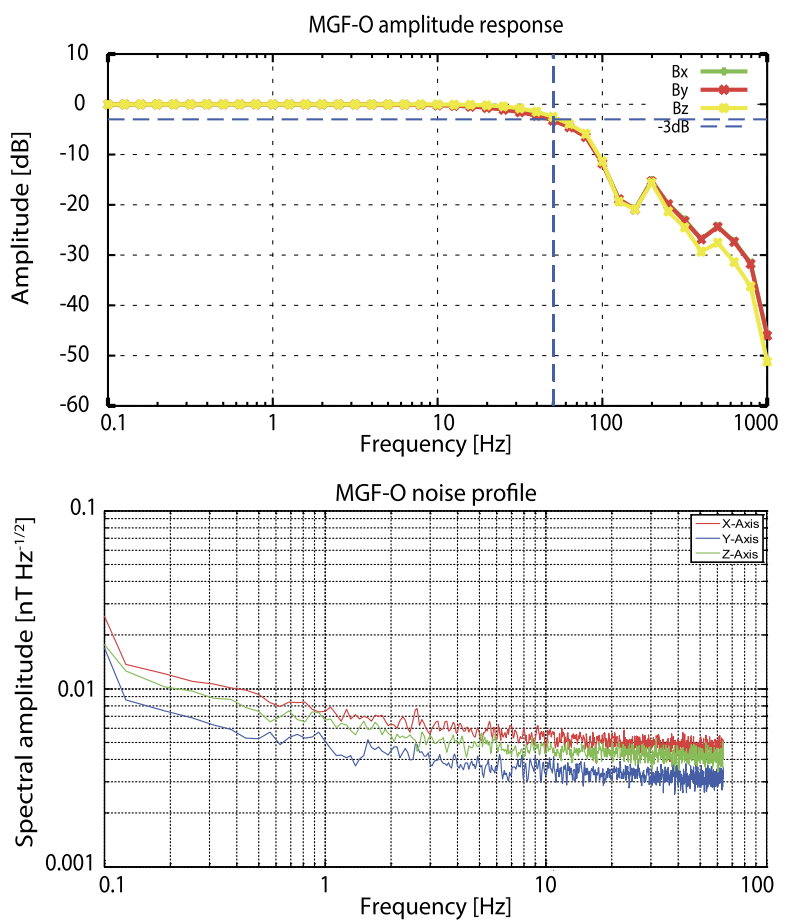

spectral amplitude in units of $\mathrm{nT} / \mathrm{Hz}^{1 / 2}$ exhibits a moderate power-law curve overall and a flattening at higher frequencies (above $10 \mathrm{~Hz}$ ). The noise profile represents the individual ring-core property.

\subsection{Inboard magnetometer MGF-I}

The inboard magnetometer MGF-I is an analogue fluxgate magnetometer of conventional type. It is designed and manufactured by Institute of Space and Astronautical Science (ISAS), Japan Aerospace Exploration Agency (JAXA) from a heritage of magnetometers for the Japanese space missions such as Akebono (Fukunishi et al. 1990), Geotail (Kokubun et al. 1994), Nozomi (Yamamoto and Matsuoka 1998).

The MGF-I sensor is made up from three-identical single-axis elements. Each sensor has an excitation coil (or driving coil) and a pick-up-feedback coil. The driving coil is wound along the circumference of ringcore. The ringcore has a diameter of $20 \mathrm{~mm}$, and its material is nickel-molybdenum permalloy. The three sensors are integrated in line onto a ceramic stand. The sensor unit is then protected by box-shape cover made of multi-layer aluminumcoated polyamide film.

The driving circuit generates a $11-\mathrm{kHz}$ pulse current. The amplitude of the current is about $700 \mathrm{~mA}$ (from peak to peak). It is optimized to save the electric power and to operate the magnetometer in a wide range of temperatures. The average power consumption is 141 $\mathrm{mW}$ in the sensor unit. The input signal to the driving circuit is generated by FPGA using an $8-\mathrm{MHz}$ crystal master clock. The signal induced at the pick-up-feedback coil is amplified (by a preamplifier) efficiently at the second harmonic, $22 \mathrm{kHz}$, using a bandpass filter.

MGF-I has a dynamic range of $\pm 2000 \mathrm{nT}$. Its resolution is digitalized to 20 bit using analogue-to-digital converter (ADC), i.e., an accuracy of 3.8 pT (per axis) in the magnetic 
Fig. 4 (Top) Filter properties of the analogue-digital converter determining the frequency characteristics of MGF-I. Vertical solid and broken lines indicate the frequencies of $-3 \mathrm{~dB}$ and $-18 \mathrm{~dB}$ reductions, respectively. (Bottom) the noise spectrum of analogue output of MGF-I. The y axis ranges are same as that in Fig. 3

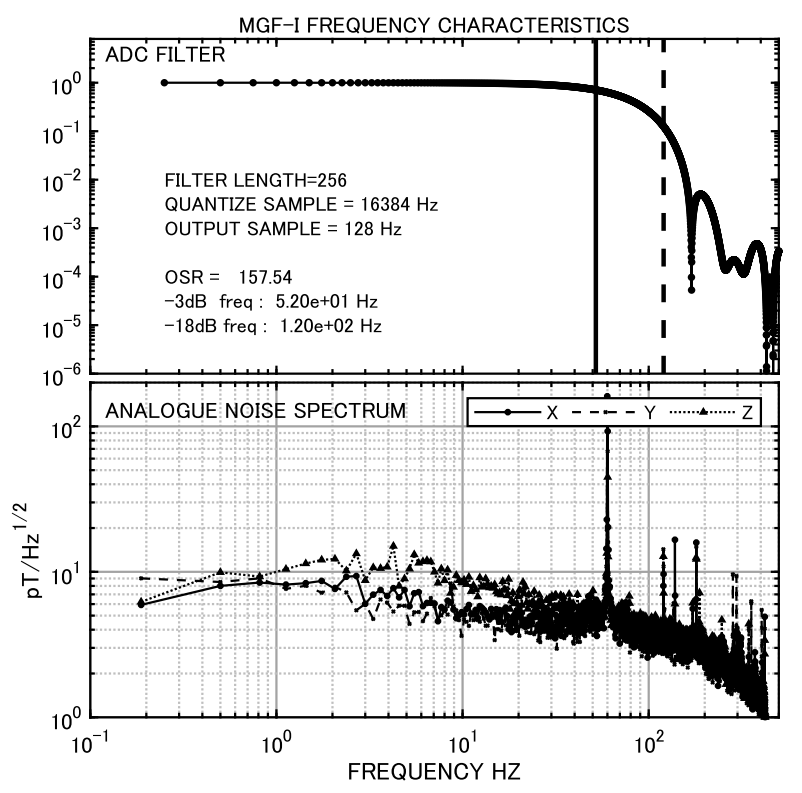

field measurement. A radiation-tolerant delta-sigma ADC circuit has been developed for MGF-I to perform the measurements with a resolution of 20 bits and a sampling rate of $128 \mathrm{~Hz}$. Detailed electronics design and block diagrams for MGF-I are given in Baumjohann et al. (2010) and Matsuoka et al. (2013).

The amplitude response of the analogue part has the cut-off $(-3 \mathrm{~dB})$ at $200 \mathrm{~Hz}$, much higher than the output sampling frequency. The resultant frequency characteristics of MGFI is predominantly determined by the design of the digital filter implemented in the ADC. The top panel of Fig. 4 shows the filter properties of the ADC. It has the cut-off $(-3 \mathrm{~dB})$ at $52 \mathrm{~Hz}$, and therefore a very similar behavior to that of MGF-O, that is, an almost 100-\% response up to a frequency of about $10 \mathrm{~Hz}$ and decrease in the response at higher frequencies. The amplitude response of the digital filter (Fig. 4 top panel) is equally applied to the three MGF-I sensors (thus showing only one data plot).

The bottom panel of Fig. 4 shows the noise spectrum of analogue output of MGF-I, namely measured for the input signal to the ADC. Peaks at $60 \mathrm{~Hz}$ and higher frequencies represent interference by the power supply and measurement environment. The noise of $\mathrm{x}-$ and $\mathrm{y}$-axis sensor is just below $10 \mathrm{pT} / \mathrm{Hz}^{1 / 2}$ in the frequencies from 0.2 to $3 \mathrm{~Hz}$. It gradually decreases with the frequency above $3 \mathrm{~Hz}$. The noise of z-axis sensor is slightly higher than $\mathrm{x}$ - and $\mathrm{y}$-axis sensors and has a moderate peak at around $4 \mathrm{~Hz}$. It might be caused by the configuration of the experiment in which the z-axis sensor was placed most closely to the opening edge of the magnetic shielding box, although the definite reason is not clear. We have to note that the noises at frequencies above the cut-off of the ADC are filtered out, and suppressed in the final digital output. Therefore the resultant noise profile exhibits a flatter curve in the frequency domain up to a frequency of about $50 \mathrm{~Hz}$, followed by a sudden spectral break at frequencies higher than $50 \mathrm{~Hz}$. The low-frequency noise (below $3 \mathrm{~Hz}$ ) is interpreted as the remanent DC and smoothly-changing field during the test that could not be eliminated in the shielding box. 


\section{Calibration}

\subsection{Overview}

Fluxgate magnetometers do not perform absolute measurements and need to undergo ground calibration and in-flight calibration (e.g., Balogh 2010). The measured magnetic field vector differs from the true ambient field due to various influeincing parameters (called the calibration parameters). The calibrated, ambient field is obtained from the sensor-output field by taking account of the offsets and sensitivities (or gains) of the sensors, non-orthogonality (elevation angles and azimuthal angle) of sensor-axis directions, and misalignment to the spacecraft spin-axis and rotation angle in the spin plane. An overview of magnetometer calibration is described here in a simplified fashion to introduce the calibration parameters and the associated coordinate systems. The physical behavior of magnetometers and the variation of spacecraft attitude need to be taken into account to optimize the calibration.

The calibrated field $\mathbf{B}$ is related to the sensor-output field $\mathbf{B}_{\mathrm{s}}$ through a set of transformation matrices multiplied successively as $\boldsymbol{\Psi} \boldsymbol{\Sigma}_{\mathrm{x}} \boldsymbol{\Sigma}_{\mathrm{y}} \boldsymbol{\Gamma} \mathbf{G}$ and an offset vector $\mathbf{O}_{\mathrm{s}}$ as (Kepko et al. 1996; Plaschke et al. 2019)

$$
\mathbf{B}=\Psi \Sigma_{\mathrm{x}} \Sigma_{\mathrm{y}} \Gamma \mathbf{G}\left(\mathbf{B}_{\mathrm{s}}-\mathbf{O}_{\mathrm{s}}\right)
$$

Here, the transformation is performed in the following order. First, the sensor output is corrected for the offset vector $\mathbf{O}_{\mathrm{s}}$ and the gain matrix with the gain ratio in the spin plane $g$ (the relative gain) and the absolute gains in the spin plane $G_{\mathrm{p}}$ and along the spin axis $G_{\mathrm{a}}$ in the sensor axis-aligned coordinate system (the coord-a system in Fig. 5).

$$
\mathbf{G}=\left(\begin{array}{ccc}
g G_{\mathrm{p}} & 0 & 0 \\
0 & G_{\mathrm{p}} / g & 0 \\
0 & 0 & G_{\mathrm{a}}
\end{array}\right)
$$

Second, the magnetic field vector is transformed into the sensor package system (the coordb system in Fig. 5) with the $\mathrm{Pz}$ axis in the sensor-3 direction and the $\mathrm{Px}-\mathrm{Pz}$ plane spanning the sensor- 1 and sensor- 3 directions. The transformation is made by the non-orthogonality matrix with two elevation angles $\theta_{1}$ and $\theta_{2}$ (with respect to the sensor-3 direction) and an azimuthal separation angle $\phi_{12}$ in the Px-Py plane, which is the angle between the sensor-1 and the sensor- 2 directions projected onto the plane normal to the sensor- 3 direction

$$
\boldsymbol{\Gamma}=\left(\begin{array}{ccc}
\sin \theta_{1} & 0 & \cos \theta_{1} \\
\cos \phi_{12} \sin \theta_{2} & \sin \phi_{12} \sin \theta_{2} & \cos \theta_{2} \\
0 & 0 & 1
\end{array}\right)^{-1}
$$

Third, the field vector is transformed into the (spinning) spacecraft spin axis-aligned system (the coord-c system in Fig. 5) by rotating the sensor package $\mathrm{Pz}$ axis to the projection of spin axis onto the sensor package $\mathrm{Py}-\mathrm{Pz}$ plane by the angle $\sigma_{\mathrm{Py}}$ (rotation around the sensor package Px axis) with the rotation matrix $\boldsymbol{\Sigma}_{\mathrm{y}}$

$$
\boldsymbol{\Sigma}_{\mathrm{y}}=\left(\begin{array}{ccc}
1 & 0 & 0 \\
0 & \cos \sigma_{\mathrm{Py}} & -\sin \sigma_{\mathrm{Py}} \\
0 & \sin \sigma_{\mathrm{Py}} & \cos \sigma_{\mathrm{Py}}
\end{array}\right)
$$


Fig. 5 Coordinate systems used in the magnetometer calibration

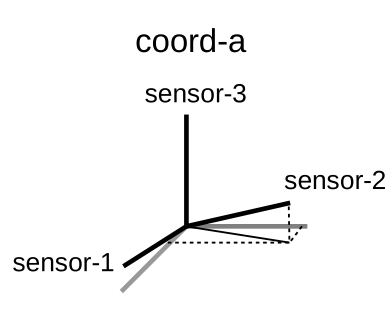

coord-c

$\mathrm{z}$ (spin axis)

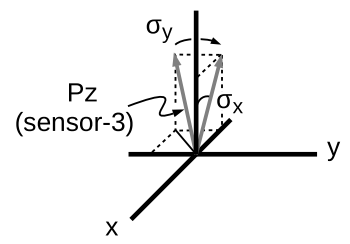

coord-b

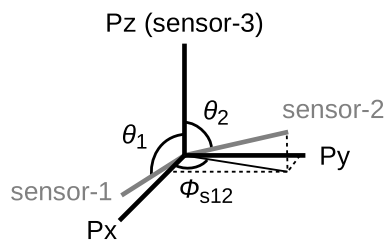

coord-d

$Z$ (spin axis)

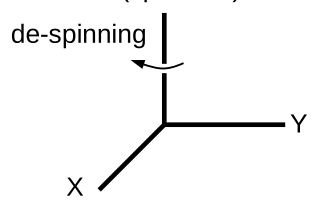

and further by rotating around the Py axis to the spin axis by the angle $\sigma_{\mathrm{x}}$ with the rotation matrix $\boldsymbol{\Sigma}_{\mathrm{x}}$

$$
\boldsymbol{\Sigma}_{\mathrm{x}}=\left(\begin{array}{ccc}
\cos \sigma_{\mathrm{Px}} & 0 & -\sin \sigma_{\mathrm{Px}} \\
0 & 1 & 0 \\
\sin \sigma_{\mathrm{Px}} & 0 & \cos \sigma_{\mathrm{Px}}
\end{array}\right)
$$

Finally, the field vector is transformed into the de-spun (inertial) spacecraft spin axis-aligned system (the coord-d system in Fig. 5) by rotating by the fixed angle $\phi_{\mathrm{a}}$ and the spin phase $\omega t$ (where $\omega$ denotes the despinning angular frequency and $t$ the time) around the spin axis. The transformation is made by the rotation matrix $\Psi$

$$
\boldsymbol{\Psi}=\left(\begin{array}{ccc}
\cos \left(\phi_{\mathrm{a}}+\omega t\right) & -\sin \left(\phi_{\mathrm{a}}+\omega t\right) & 0 \\
\sin \left(\phi_{\mathrm{a}}+\omega t\right) & \cos \left(\phi_{\mathrm{a}}+\omega t\right) & 0 \\
0 & 0 & 1
\end{array}\right)
$$

There are twelve calibration parameters:

- three offsets $\left(\mathrm{O}_{1}, \mathrm{O}_{2}\right.$, and $\left.\mathrm{O}_{3}\right)$,

- relative gain $(g)$, absolute gain in the spin plane $\left(G_{\mathrm{p}}\right)$ and that along the spin axis $\left(G_{\mathrm{a}}\right)$,

- two elevation angles $\left(\theta_{1}=\frac{\pi}{2}+\delta \theta_{1}\right.$ and $\left.\theta_{2}=\frac{\pi}{2}+\delta \theta_{2}\right)$ which the sensor- 1 and sensor- 2 directions make to the sensor-3 direction, respectively

- azimuthal angle $\phi_{12}=\frac{\pi}{2}+\delta \phi_{\mathrm{s} 12}$ which is the projection of the angle between the sensor1 and sensor- 2 directions onto the plane normals to the sensor-3 direction (the Px-Py plane),

- two tilt angles describing the spin axis ( $\sigma_{\mathrm{Px}}$ and $\sigma_{\mathrm{Py}}$ ), where $\sigma_{\mathrm{Py}}$ is the angle between the sensor-3 direction (Pz direction) and the projection of the spin axis onto the Py-Pz plane, and $\sigma_{\mathrm{Px}}$ is the angle between the spin axis and the direction of $\sigma_{\mathrm{Py}}$,

- spin-plane rotation angle $\phi_{\mathrm{a}}$. 
Note that the orthogonality nearly holds such that the elevation and azimuthal angles exhibit only a small deviation from $90^{\circ}$,

$$
\begin{gathered}
\delta \theta_{1}=\theta_{1}-\frac{\pi}{2} \sim 0 \\
\delta \theta_{2}=\theta_{2}-\frac{\pi}{2} \sim 0 \\
\delta \phi_{\mathrm{s} 12}=\phi_{\mathrm{s} 12}-\frac{\pi}{2} \sim 0 .
\end{gathered}
$$

Also the tilt angles are small and close to zero,

$$
\begin{aligned}
& \sigma_{\text {Px }} \sim 0 \\
& \sigma_{\text {Py }} \sim 0 .
\end{aligned}
$$

The relative gain and the two absolute gains are close to unity,

$$
\begin{aligned}
g & \sim 1 \\
G_{\mathrm{p}} & \sim 1 \\
G_{\mathrm{a}} & \sim 1 .
\end{aligned}
$$

The calibration parameters described above are not constant but depend on, for example, the temperature at the sensors and electronics. This is because the sensor mechanical structure responds to thermal changes by deformation and non-uniform thermal expansion. Along the spacecraft trajectory, during cruise as well as in orbit, the temperature strongly evolves. In addition to temperature effects, the sensor materials age over mission duration and this also changes the calibration parameters. There are several more causes outside the magnetometer which would change the calibration parameters. Especially the alignment variation will be caused by the deformation of the mast. Matsuoka et al. (2019) presents an estimation of the deformation of the mast on the Arase spacecraft and its temporal variation. Moreover, the stray field from the spacecraft may exhibit major time-dependent variations along the orbit.

\subsection{Ground calibration}

Both MGF-O and MGF-I went through ground calibrations prior to the launch. The following procedure was taken for the ground calibration of MGF-O (The same procedure as that for the MPO magnetometers):

1. Calibration of offset, noise, relative gain, and phase tuning in low field environment at temperatures from $-100{ }^{\circ} \mathrm{C}$ up to $180^{\circ} \mathrm{C}$. The calibration was conducted in a magnetic shielding-based facility at the Space Research Institute in Graz, Austria.

2. Calibration of offset, absolute gain, orthogonality, and transfer function at temperatures from $-100{ }^{\circ} \mathrm{C}$ up to $180{ }^{\circ} \mathrm{C}$ in a Braunbek coil-based facility at the Technische Universität Braunschweig, Germany.

Real measurements have shown that the MGF-O temperature was $-63{ }^{\circ} \mathrm{C}$ during the first turn-on in cruise, and in the range between $-40^{\circ}$ and $-50^{\circ}$ during the Earth flyby. The lowest MGF-O sensor temperature expected for the orbit around Mercury is about $34{ }^{\circ} \mathrm{C}$ (at 
aphelion) after thermal analysis, while the highest temperature is expected about $159{ }^{\circ} \mathrm{C}$ (at perihelion with the sensor on).

The MGF-I instrument went through four tests for the calibration.

1. Calibration for phase tuning and analogue-part transfer function, as well as the noise measurement, in low field (noise) environment in a shielding box.

2. Calibration of offset and relative sensitivity at temperatures from $-20^{\circ} \mathrm{C}$ up to $180{ }^{\circ} \mathrm{C}$ in a low field (i.e., only noise) environment. The calibration was conducted in the shielding room at JAXA Sagamihara.

3. Calibration (at room temperature) of the absolute sensitivity and orthogonality in JAXA Tsukuba magnetic test facility.

Real measurements have shown that the MGF-I temperature was $-32{ }^{\circ} \mathrm{C}$ during the first turn-on in cruise. The temperature was between $-20^{\circ} \mathrm{C}$ and $-25^{\circ} \mathrm{C}$ during the Earth flyby. The lowest MGF-I sensor temperature expected for the orbit around Mercury is about $19{ }^{\circ} \mathrm{C}$ (at aphelion) and the highest is about $154^{\circ} \mathrm{C}$ (at perihelion).

Common measurements were performed in addition for both MGF-O and MGF-I:

1. A joint calibration for the absolute gain and orthogonality at the room temperature in the coil facilities (magnetic test site) at JAXA Tsukuba.

2. Synchronization test between MGF-O and MGF-I at JAXA Sagamihara.

3. Functional checks in the shielding dome and spacecraft integration hall at JAXA Sagamihara, in the spacecraft integration hall at European Space Research and Technology Centre (ESTEC), as well as at the launch site in Kourou.

Since the dynamic range of the sensors is too low to test against the full Earth field on the ground, field compensation coils were used to get the sensor within the operational dynamic range. A compensation coil structure was used for the test at JAXA Sagamihara, and a portable compensation coil system was used for the tests at ESTEC and the launch site. Time synchronization between MGF-O and MGF-I is confirmed to be well below the requirement of $800 \mu \mathrm{s}$.

\subsection{Temperature dependence}

One of the main results from the ground calibration activities is the knowledge on temperature dependence (also called the drift) of calibration parameters. Dependence of MGF-O calibration parameters (noise level, offset, sensitivity, and non-orthogonality) on the sensor temperature is displayed in Fig. 6. The lessons from the MGF-O ground calibration are (1) the noise level becomes lower at higher temperatures; (2) the offsets have a moderate temperature drift, yet staying within $1 \mathrm{nT}$ for a change in the sensor temperature over $100{ }^{\circ} \mathrm{C}$; (3) the absolute gains (sensitivities) show a linear dependence on the sensor temperature (4) non-orthogonality between the sensor angles may be regarded as nearly constant with moderate variations of the order of $0.01^{\circ} \sim 10^{-3} \mathrm{rad}$ in the temperature range between $-100{ }^{\circ} \mathrm{C}$ and $180{ }^{\circ} \mathrm{C}$.

Results from the MGF-I ground calibration about the dependences of offset and sensitivity (gain) on the sensor temperature are displayed in Fig. 7. The variation was measured in 3 distinct runs: the first high temperature cycle ("hot 1"), the second one ("hot 2"), and the low temperature cycle ("cold"). Since the expected minimum and maximum sensor temperatures in the orbit around Mercury are $18.7^{\circ} \mathrm{C}$ and $153.6^{\circ} \mathrm{C}$, the temperature range has good margin to examine the sensor performance in the actual operation condition. The offset was examined as the variation from that at the room temperature. The drift is less than 3,6 and 4 
Fig. 6 Temperature dependence of the spectral noise level and calibration parameters (offsets, sensitivities or absolute gains, and orthogonality angles) obtained from the MGF-O ground calibration. Here, the temperature means the sensor temperature

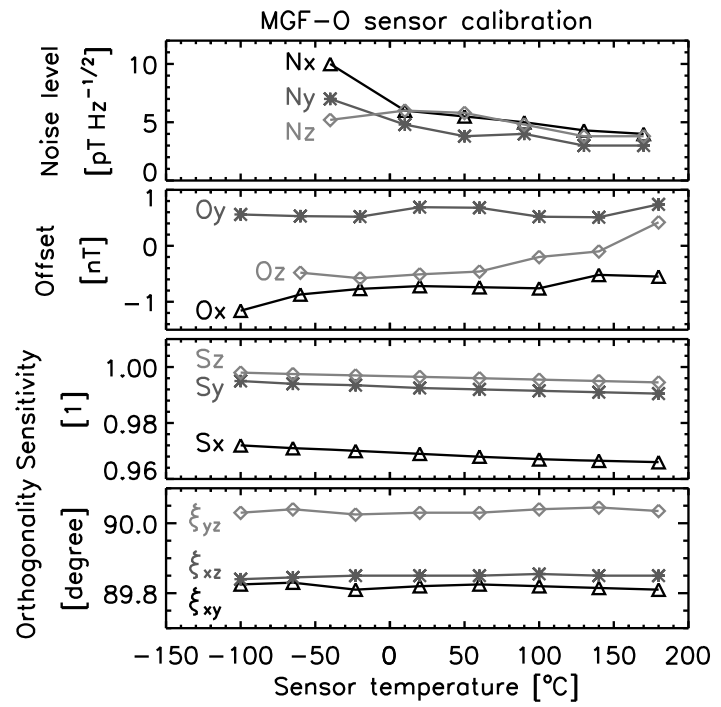

$\mathrm{nT}$ for the $\mathrm{x}, \mathrm{y}$ and $\mathrm{z}$ axes, respectively, for a change in temperature of $200^{\circ} \mathrm{C}$. The sensitivity was measured only in "hot" cycles due to the test configuration reason. The sensitivity drift is nearly linear to the temperature, and shows the same response to the temperature between the two calibration runs, and is reproducible. The dependences of noise and orthogonality on the sensor temperature were not examined for MGF-I because the experiment was not feasible in the facilities in Japan.

To sum up, the following characteristics are drawn as a conclusion of the MGF-O and MGF-I ground calibration.

1. MGF-O Noise floor is found to be less than $7 \mathrm{pT} / \mathrm{Hz}^{1 / 2}$ in the temperature range between $-10{ }^{\circ} \mathrm{C}$ and $170{ }^{\circ} \mathrm{C}$ which is relevant for the Mercury environment (after thermal calculation).

2. Gain drift is regarded linear on both MGF-O and MGF-I, and is well reproducible to an accuracy down to the order of $10^{-3}$.

3. Sensor orthogonality is stable (angular variation within $0.01^{\circ}$ ) over the entire sensor temperature range.

4. Offset drift is less than $1 \mathrm{nT}$ (MGF-O) and at most $3 \mathrm{nT}$ (MGF-I) within a sensor temperature change of $100{ }^{\circ} \mathrm{C}$ relevant for Mercury's environment.

\subsection{Spacecraft-field determination}

All the components and instruments on the Mio spacecraft are required to follow the electromagnetic compatibility component design criteria. For this reason, the Mio spacecraft units went through the magnetic cleanliness test on two different levels. The first was the unit level test which was applied to different models (breadboard models or equivalent, engineering models or qualification models, and flight models). A model of spacecraft static field was constructed based on the results from the unit level tests. The static field intensity is estimated about $0.15 \mathrm{nT}$ at the position of the MGF-O sensor and about $0.9 \mathrm{nT}$ at the position of the MGF-I sensor according to the model created from the unit-level measurement results. The second is the system level test. It was conducted for the flight models of the 
Fig. 7 Ground calibration results for MGF-I sensor. Offset is evaluated as the variation from that at the room temperature.

Sensitivity (gain) is the relative value to that at the room temperature

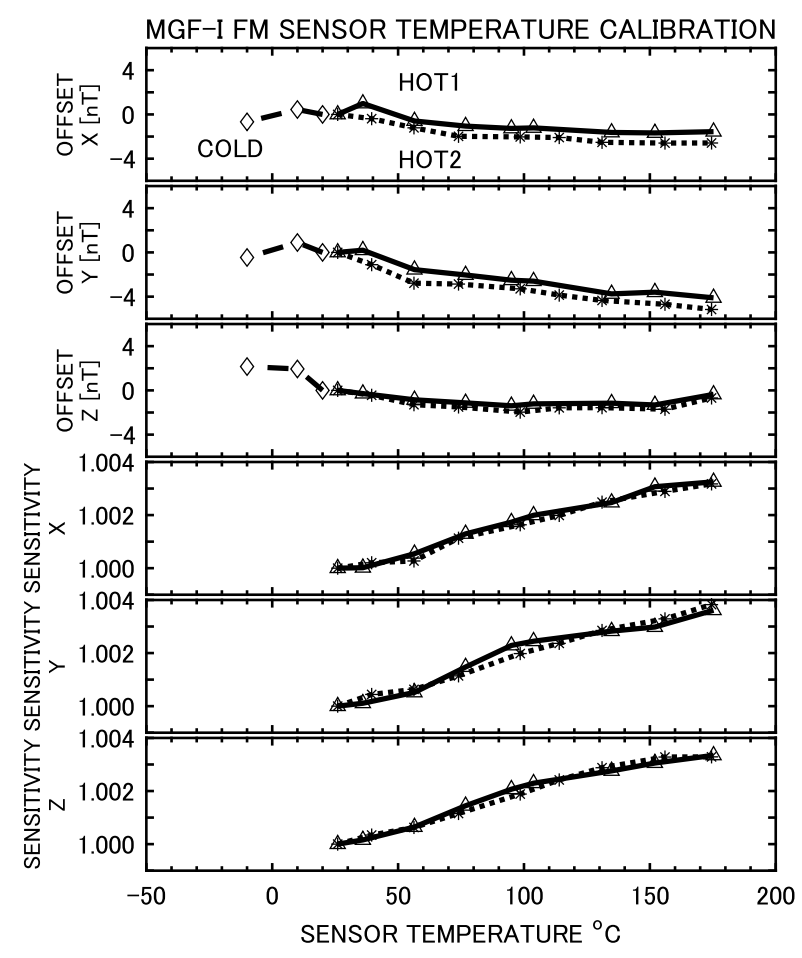

whole spacecraft during the electrical interface check test phase and for the whole system during the assembly, integration, and verification. The spacecraft generates magnetic fields both as static and fluctuating fields.

The resultant static and fluctuating fields of the Mio spacecraft were measured during the flight model integration test period. The static field measurements were made at 42 different points those are distributed on a spherical surface with a distance to the spacecraft center of $2.4 \mathrm{~m}$. The measurement location was at spherical grids every $45^{\circ}$ in azimuth (from $-180^{\circ}$ to $\left.180^{\circ}\right)$ and every $30^{\circ}$ in elevation $\left(-90^{\circ}\right.$ to $90^{\circ}$ ). The azimuth is defined as the phase angle in the spacecraft xy plane and elevation angle is as the angle from the xy plane. The MAST deployment direction corresponds to the azimuth $0^{\circ}$ and elevation $0^{\circ}$.

Figure 8 shows the measured static field intensities at these 42 positions as well as the estimated intensities by the model constructed by the results from the unit level tests. Comparison between the right and left panels indicates that the model well represents the actual fields around the spacecraft. The measured fields are generally more intense than the estimated, but the mean discrepancy between the measurement and the model is only $1.2 \mathrm{nT}$. Because the Mio spacecraft has a relatively flat shape, the field intensity decreases as the measurement location moves to the poles at elevations of $90^{\circ}$ and $-90^{\circ}$. The field distribution shows an enhancement at azimuth range between $-180^{\circ}$ and $-45^{\circ}$, and it is most significant at $0^{\circ}$ azimuth. It is apparently caused by permanent magnets used in the mounted instruments which locate in these azimuth segments.

The fluctuating magnetic field generated by the spacecraft was measured at a single position, azimuth $0^{\circ}$ and zero elevation at a distance of $2.4 \mathrm{~m}$ from the spacecraft center. Three components of the magnetic field $\left(B_{\mathrm{x}}, B_{\mathrm{y}}\right.$, and $\left.B_{\mathrm{z}}\right)$ were sampled at $128 \mathrm{~Hz}$. Figure 9 shows 


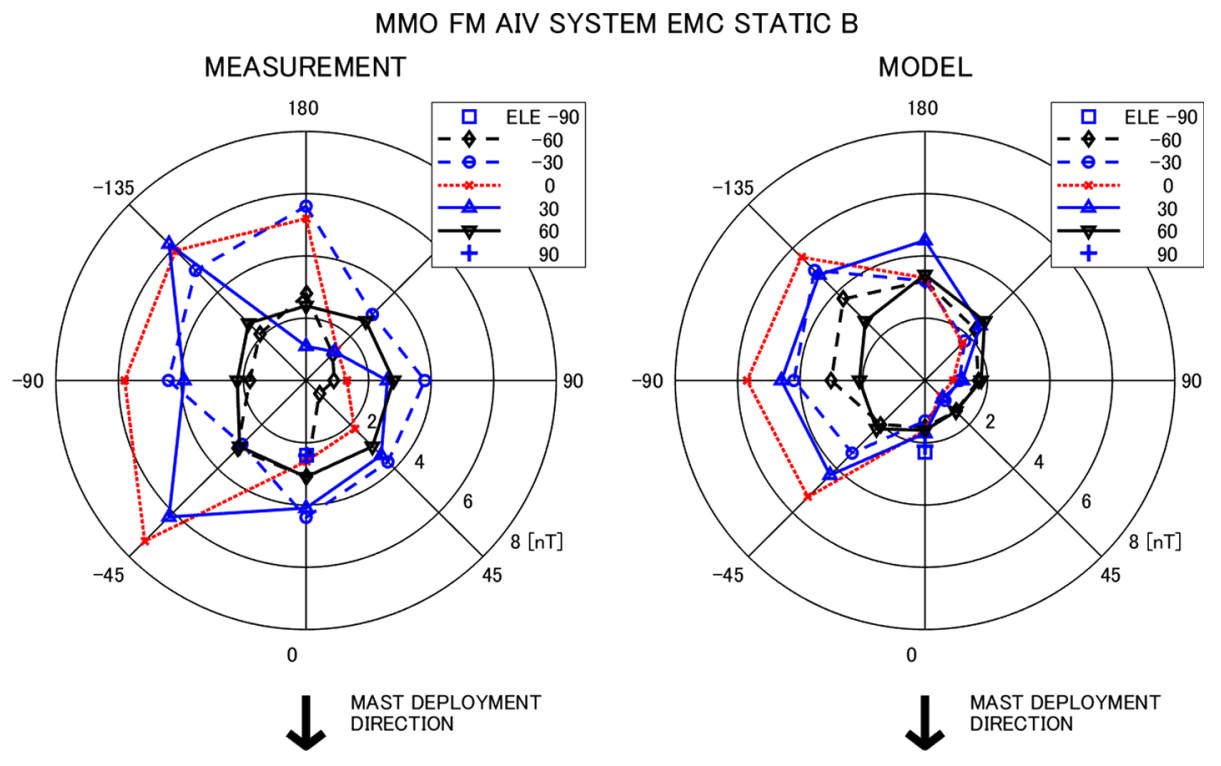

Fig. 8 Intensity of spacecraft-generated static magnetic field on the spherical surface at $2.4 \mathrm{~m}$ from the spacecraft center. The measurement location was at spherical grids every $45^{\circ}$ in azimuth (from $-180^{\circ}$ to $\left.180^{\circ}\right)$ and every $30^{\circ}$ in elevation $\left(-90^{\circ}\right.$ to $\left.90^{\circ}\right)$. The circumference angle represents the azimuth of the spacecraft. (left) Measurement result. (right) field derived from the model by the unit level tests

the time series of the measured field averaged over time windows of $15.45 \mathrm{~s}$ and standard deviation of the field in the same $15.45 \mathrm{~s}$ windows.

The large spikes in the measured field at times of 10:15 and 10:22 are caused by opening and closing of the shielding room door. And the enhancement of the standard deviation between these two times is caused by the rotation of the high-gain antenna. The same phenomenon occurred in the period from 16:37 to 16:53. In the spacecraft frame the magnetic noise from the rotating antenna has purely sinusoidal waveform synchronizing the spin period. In the orbit where the Mio spacecraft rotates, the antenna is static and therefore generates DC field in the rest frame. The offset would be $0.08 \mathrm{nT}$ when it is measured by MGF-O sensor after the MAST deployment. The small jump in $B_{\mathrm{x}}$ at 20:53 is caused by the turn-on of the electronic device to amplify RF signals.

The field exhibits gradual changes over a time scale of hours. This change is caused by the drift of the ground support magnetometer offset and the background field in the shielding room. The standard deviations are nearly constant through the test interval except the periods of the antenna rotation. They apparently represent the environment noise since they have the same intensity even before the turning on of the spacecraft (at 10:20). From Fig. 9 we conclude that the time variation of the spacecraft field was found to be sufficiently stable.

\subsection{In-flight calibration plan}

Eight calibration parameters out of the twelve discussed in Sect. 4.1 can be found using in-flight calibration by making use of the spin-stabilization of Mio, whereby an incorrect determination of those parameters automatically generates harmonics of the spacecraft spin 


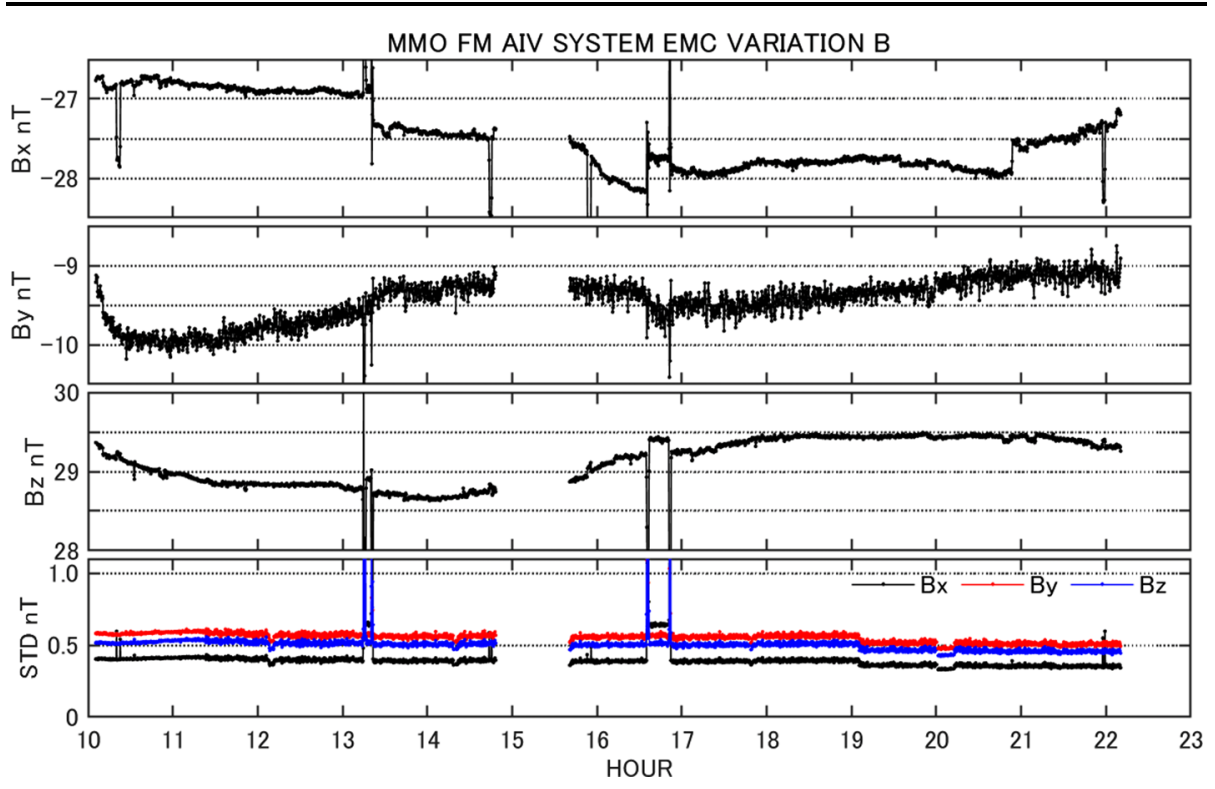

Fig. 9 Time series of magnetic field at a distance of $2.4 \mathrm{~m}$ from the spacecraft center. Top three panels are three components of the magnetic field averaged over time windows of $15.45 \mathrm{~s}$. The bottom panel shows the standard deviations of $128-\mathrm{Hz}$ data in the same $15.45 \mathrm{~s}$ windows

frequency in the de-spun magnetometer data. The Mio magnetometer calibration will follow the fine-tuned approach by Plaschke et al. (2019) which is successfully used for the calibration of the fluxgate magnetometers on board the Magnetospheric Multiscale satellites (Russell et al. 2016).

The remaining four calibration parameters (i.e., absolute gains in the spacecraft spin plane and along the spin axis, the spin axis component of offset, and the rotation angle of the sensor around the spin axis) need to be calculated using a set of more advanced techniques or taken from on-ground measurements.

The offset in the direction of the spacecraft spin axis will be determined either by using the nearly incompressible nature of Alfvén waves in the solar wind as a constraint (Hedgecock 1975; Leinweber et al. 2008) or using highly compressible fluctuations such as mirror mode waves in the magnetosheath or compressive wave trains in the shock-upstream region as a guide to find the mean field direction (Plaschke and Narita 2016; Plaschke et al. 2017).

The two gain parameters will be taken from ground calibration. This is a viable solution because the magnetic field at Mercury is sufficiently small and the results from the ground calibration (including the gain drift with sensor temperature) are very deterministic (Sect. 4.3). The rotation angle of the sensor around the spacecraft spin axis cannot be obtained in flight, either, but the error is guaranteed by design to be within $0.5^{\circ}$ if the mast is extended nominally.

\section{Measurement uncertainties}

The MGF magnetometer exhibits various kinds of measurement uncertainties. Stochastic error comes from the sensor noise, which is about $0.04 \mathrm{nT}$ (root-mean-square in the range between $0.1 \mathrm{~Hz}$ and $10 \mathrm{~Hz}$ ). The uncertainty sources for the systematic error are studied quan- 
titatively in this section, and an outline is given as to how these sources combine through the calibration process to assess the final error on the component of each calibrated magnetic field vector.

Systematic error occurs due to the uncertainties in calibration procedure. The magnetometer data are corrected for offsets (including the spacecraft DC field), gains, deviations from the ideal orthogonal coordinate system, spacecraft spin axis direction with respect to the sensor reference direction and rotation angle around the spacecraft spin axis as described in Sect. 4.1. The error estimate is performed conceptually with the following steps. First, we set a model ambient field in the $\mathrm{X}-\mathrm{Z}$ plane in the spacecraft-fixed inertial frame (the coord-d system in Fig. 5) with the spin-plane magnetic field component $B_{\mathrm{p}}$ and the spin-axis component $B_{\mathrm{a}}$. Second, the sensor-output field is computed by reverting the transformations in Eq. (1) from the coord-d system into coord-c, coord-b, and further to coord-a. Third, the sensor-output field is transformed back to the initial coordinate system (coord-a) allowing errors of calibration parameters. This reconstructed field is represented in the spacecraftfixed inertial frame, yet the unit vectors may be different from that of the coord-a system due to the errors. We refer to the three components of the reconstructed field as the spinplane primary component $B_{\mathrm{X}^{\prime}}$, spin-plane residual component $B_{\mathrm{Y}^{\prime}}$, and spin-axis component $B_{Z^{\prime}}$.

For a nearly-orthogonal unit-gain sensor system, the uncertainty of reconstructed field is obtained by perturbing Eqs. (24)-(26) in Plaschke et al. (2019) to the first order. The quantitative error estimate is given as follows:

$$
\begin{aligned}
\left|\Delta B_{\mathrm{X}^{\prime}}\right| \leq & \Delta O_{1 / 2}+B_{\mathrm{p}}\left(\Delta G_{\mathrm{p}}+\Delta g+\Delta\left(\delta \phi_{12}\right)\right) \\
& +B_{\mathrm{a}}\left(\Delta \sigma_{\mathrm{Px} / \mathrm{y}}+\Delta\left(\delta \theta_{1 / 2}\right)\right) \\
\left|\Delta B_{\mathrm{Y}^{\prime}}\right| \leq & \Delta O_{1 / 2}+B_{\mathrm{p}}\left(\Delta G_{\mathrm{p}}+\Delta g+2 \Delta \phi_{12}+\Delta \phi_{\mathrm{a}}\right) \\
& +B_{\mathrm{a}}\left(\Delta \sigma_{\mathrm{Px} / \mathrm{y}}+\Delta\left(\delta \theta_{1 / 2}\right)\right) \\
\left|\Delta B_{\mathrm{Z}^{\prime}}\right| \leq & \Delta O_{3}+B_{\mathrm{p}} \Delta \sigma_{\mathrm{Px} / \mathrm{y}}+B_{\mathrm{a}} \Delta G_{\mathrm{a}},
\end{aligned}
$$

where $\Delta B_{X^{\prime}}$ is the error of spin-plane primary component (presumed to be the spin-plane component of the ambient field), $\Delta B_{\mathrm{Y}^{\prime}}$ is the error of residual component in the spin plane (which ideally vanishes if there is no calibration error), and $\Delta B_{Z^{\prime}}$ is the error of spin-axis component. Absolute errors come from the offset determination uncertainty in the spin plane $\Delta O_{1 / 2}$ (referring to the larger value of $\Delta O_{1}$ and $\Delta O_{2}$ ) and along the spin axis $\Delta O_{3}$. Relative errors contain that of gains and sensor angles, and depend on the ambient magnetic field with the spin-plane component $B_{\mathrm{p}}$ and the spin-axis component $B_{\mathrm{a}}$.

Uncertainty of the MGF calibration parameters are summarized in Table 3, based on the lessons from in-flight calibration for the spinning spacecraft (Plaschke et al. 2019) and offset determination in the spin-axis direction (Plaschke 2019; Schmid et al. 2020). Eight parameters $\left(O_{1}, O_{2}, g, \sigma_{\mathrm{Px}}, \sigma_{\mathrm{Py}}, \delta \theta_{1}, \delta \theta_{2}, \delta \phi_{12}\right)$ can be determined from the in-flight calibration making use of spacecraft spin. The spin-axis offset $\mathrm{O}_{3}$ can also be determined in-flight in the solar wind (either making use of nearly-incompressible field fluctuations or highlycompressible fluctuations. Ground calibration results are used for the parameters $G_{\mathrm{p}}, G_{\mathrm{a}}$, and $\phi_{\mathrm{a}}$. by referring to the sensor (and electronics) temperature.

The uncertainty formulae (Eqs. (15)-(17)) are graphically displayed in Fig. 10 for the calibration parameter errors in Table 3 . The error estimate curves represent the largest error scenario, that is, the error of spin-plane residual component is evaluated for an ambient field in the spin-plane, and the error of spin-axis component is for an ambient field in the spinaxis direction. The systematic error has two distinct domains. In a low-field environment 
Table 3 Uncertainties of MGF calibration parameters

\begin{tabular}{lll}
\hline Parameter & Symbol & Error upper limit \\
\hline Spin-plane offsets & $O_{1}, O_{2}$ & $0.1 \mathrm{nT}$ \\
Spin-axis offset (solar wind) & $O_{3}^{(\mathrm{sw})}$ & $0.2 \mathrm{nT}$ \\
Spin-axis offset (magnetosphere) & $O_{3}^{(\mathrm{ms})}$ & $1 \mathrm{nT}$ \\
Spin-plane absolute gain & $G_{\mathrm{p}}$ & $10^{-3}$ \\
Spin-axis absolute gain & $G_{\mathrm{a}}$ & $10^{-3}$ \\
Spin-plane gain ratio & $g$ & $10^{-4}$ \\
Sensor elevation angles & $\theta_{1}, \theta_{2}$ & $10^{-3} \mathrm{rad}$ \\
Sensor azimuthal angle & $\phi_{12}$ & $10^{-3} \mathrm{rad}$ \\
Sensor-3 angles to the spin axis & $\sigma_{\mathrm{Px}}, \sigma_{\mathrm{Py}}$ & $10^{-4} \mathrm{rad}$ \\
Spin-plane rotation angle & $\phi_{\mathrm{a}}$ & $10^{-2} \mathrm{rad}$ \\
\hline
\end{tabular}

Fig. 10 Uncertainty of calibrated MGF magnetometer data as a function of the ambient magnetic field. Top panel displays the error of spin-plane components ("primary" stands for the reconstructed ambient field direction in the spin plane $\Delta B_{\mathrm{X}^{\prime}}$ and "residual" for the rest direction in the spin plane $\left.\Delta B_{\mathrm{Y}^{\prime}}\right)$. Bottom panel displays the error of spin-axis component $\Delta B_{\mathrm{Z}^{\prime}}$ under the magnetospheric and solar wind conditions

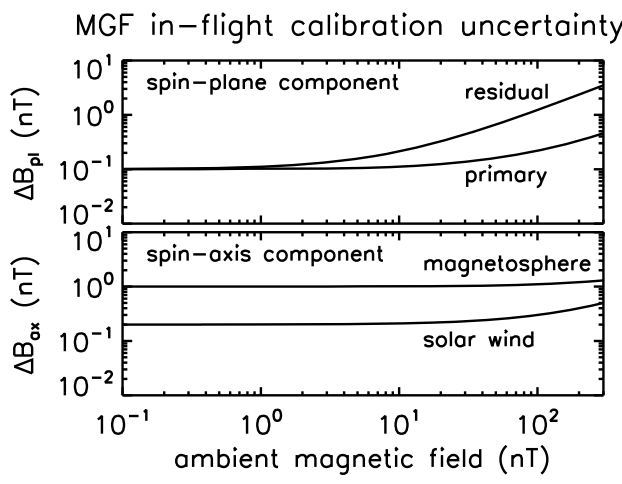

(typically for an ambient magnetic field below $10 \mathrm{nT}$ ), the offset errors are the dominant uncertainty component. The largest offset error is in the spin-axis direction, in particular when the spacecraft is in the magnetosphere. In a high-field (above $10 \mathrm{nT}$ ), in contrast, the gain errors (in the both absolute and relative senses) and angle errors (sensor directions; spin-axis direction, rotation angle in the spin plane) become dominant as relative error, and the uncertainty of calibrated data grows together with the magnitude of ambient field. The largest relative error (in the high-field case) comes from the rotation angle in the spin plane (which is the uncertainty of magnetometer mast extension direction, designed to be within $0.5^{\circ} \sim 10^{-2} \mathrm{rad}$.

The use of the uncertainty formulae (Eqs. (15)-(17)) is valid not only when the calibration parameters do not change or evolve over time or along the spacecraft trajectory, but also as long as the uncertainties are large enough to cover the changes of calibration parameters. It is important to note that temperature drift can occur along the trajectory, and the calibration parameters need to be updated or tracked after the temperature variation. It is also worthwhile to note that the long-term stability of the calibration parameters needs to be studied, and this will be performed during the cruise in interplanetary space and observation phase around Mercury. 


\section{Near-Earth commissioning}

During the cruise phase the mast on Mio is stored in the twist-folded way. The side of Mio is covered by the Sun shield. This is unlike the MPO magnetometer boom, which is already deployed right after launch. The near-Earth commissioning of the MGF instrument (both MGF-O and MGF-I) was successfully carried out on 9 November 2018. The nominal operation were confirmed for both MGF-O and MGF-I. The DC offset was found to be in the range from several hundred $\mathrm{nT}$ to $1000 \mathrm{nT}$. It is interpreted as the artificial static field generated by the BepiColombo system (Mio, MPO, and Mercury Transfer Module). An AC sinusoidal signal appeared at a frequency of about $15 \mathrm{~Hz}$ in the $\mathrm{H}$-mode data with a $128-\mathrm{Hz}$ sampling rate on both MGF-O and MGF-I. The amplitude of the AC signal varied over time and the maximum was about $50 \mathrm{nT}$ peak-to-peak. By the joint review with the data from the MAG instrument on board the MPO spacecraft, the AC signal was found to be caused by two reaction wheels on MPO which only have a distance of about $50 \mathrm{~cm}$ to the MGF sensors. This quite large interference will remain dominant in the $\mathrm{H}$ and $\mathrm{M}$-mode data during the cruise phase but it will vanish completely after the separation of Mio at Mercury.

The sensor temperature was $-62{ }^{\circ} \mathrm{C}$ at MGF-O and $-30{ }^{\circ} \mathrm{C}$ at MGF-I at the time of initial turn-on. Instantaneous vector values were monitored as housekeeping. The longest stretch of MGF-O data so far were taken on 10 November 2018. It includes a superposition of fluctuating fields from the BepiColombo system and the interplanetary magnetic field (at $1 \mathrm{AU}$ and ahead of the Earth orbital motion) for a time length of about $7000 \mathrm{~s}$ and the magnetometers operating $\mathrm{M}(8 \mathrm{~Hz})$ and $\mathrm{L}$ modes (every $4 \mathrm{~s})$. Figure 11 shows a comparison of the magnetic field data obtained by the three sensors: inboard and outboard sensors on the Mio (MGF-I and MGF-O) and outboard sensor on the MPO spacecraft with deployed boom.

The values on the plots are shifted by $5 \mathrm{nT}$ for the visualization purpose. It is comforting that all the three sensors detect the magnetic field nearly in the same waveform from one sensor to another. The waveform in the MGF-I data slightly differs from that in the MGF-O and the MPO magnetometer. The mast latch release operation was successfully conducted on 6 August 2019. The full deployment of the mast will be carried out upon Mio's arrival at Mercury.

\section{Observation plan}

\subsection{Operation modes}

The MGF magnetometer uses different operational modes with different sampling rates to make best use of the limited telemetry amount for the science targets. The data format, and the purpose are defined to each operation mode as listed in Table 4. The $\mathrm{H}$ mode is triggered by events (such as magnetic reconnection), while the M1 and L modes are region-based. Also, the selective down-link is used to retrieve the high-resolution data for detailed studies upon request (e.g., reconnection, waves).

In the orbit phase near the aphelion (Fig. 12 top panel), the Mio spacecraft peri-center (about $590 \mathrm{~km}$ altitude) is located on the dayside of Mercury and the apo-center (about $6 R_{\mathrm{M}}$ ) in the magnetotail. Such an orbit configuration is ideal for studying magnetic reconnection and substorm-like disturbances of Mercury's magnetosphere in the tail region. The MGF magnetometer is operated in the $\mathrm{H}$ mode (at a sampling frequency of $128 \mathrm{~Hz}$ ) when triggered by reconnection signatures in the tail. ULF waves are studied with the M1 mode (at $8 \mathrm{~Hz}$ ) 


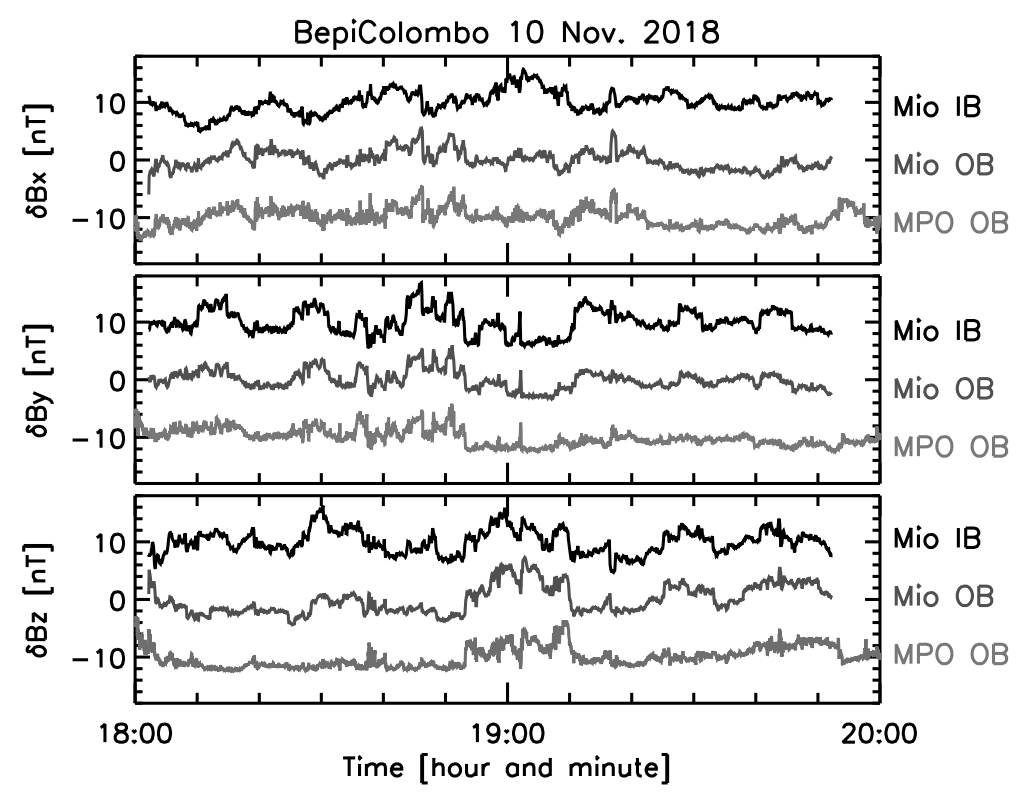

Fig. 11 Three components of magnetic field variations from MGF-I, MGF-O and MPO-OB magnetometers during the near-Earth commissioning in interplanetary space. The components are represented in MPO sensor coordinate systems. Values are shifted by an interval of $10 \mathrm{nT}$ for visualization

Table 4 Mio MGF operation modes. Sampling rate and digitization apply to the three components of magnetic field

\begin{tabular}{|c|c|c|c|}
\hline Mode & Sensor & Data format & Purpose \\
\hline \multirow[t]{2}{*}{$\mathrm{H}$} & MGF-O & $128 \mathrm{~Hz}, 20 \mathrm{bits}$ & \multirow[t]{2}{*}{ Event-triggered observations } \\
\hline & MGF-I & $128 \mathrm{~Hz}, 20 \mathrm{bits}$ & \\
\hline \multirow[t]{2}{*}{ M1 } & MGF-O & $8 \mathrm{~Hz}, 16$ bits & \multirow[t]{2}{*}{ Normal observations } \\
\hline & MGF-I & None & \\
\hline \multirow[t]{2}{*}{ M2 } & MGF-O & $4 \mathrm{~Hz}, 16$ bits & \multirow{2}{*}{$\begin{array}{l}\text { Spacecraft-field } \\
\text { determination near peri-center }\end{array}$} \\
\hline & MGF-I & $4 \mathrm{~Hz}, 16$ bits & \\
\hline \multirow[t]{2}{*}{$\mathrm{L}$} & MGF-O & 1 per spin ( 4 s), 16 bits & \multirow{2}{*}{$\begin{array}{l}\text { Solar wind measurements and } \\
\text { sinusoidal waveform fitting }\end{array}$} \\
\hline & MGF-I & 1 per spin $(4 \mathrm{~s}), 16$ bits & \\
\hline \multirow[t]{2}{*}{ CHECKOUT } & MGF-O & $128 \mathrm{~Hz}, 20 \mathrm{bits}$ & \multirow[t]{2}{*}{ Health check } \\
\hline & MGF-I & $128 \mathrm{~Hz}, 20 \mathrm{bits}$ & \\
\hline
\end{tabular}

from the night-side to the cusp regions. The planetary field is studied using the L mode (every $4 \mathrm{~s}$ ) on the dayside.

The concept of triggering mechanism for the H-mode is as follows (see Kasaba et al. 2020, for details). MGF raw data for a time length of 4-20 minutes are continuously stored into DPU data storage (128 MB capacity) together with the data from MPPE (except for ENA) and PWI-EWO. The time length for the storage depends on the capacity available 
on the data storage), and is expected to cover major boundary crossings and science target events. The raw data are copied to the $\mathrm{H}$-mode partition in the system data recorder $(2 \mathrm{~GB}$ capacity) by the commands or the on-board triggering function. The $\mathrm{H}$-mode data are retrieved by the preset command-based triggering scheme or on-board automatic-triggering scheme. Both schemes can transmit the $\mathrm{H}$-mode data before and after the trigger within a time length of 4-20 minutes. The command-based triggering has a pre-planned time sequence prior to the scientific objectives and operational phases. The automatic-triggering makes use of a set of reference parameters including the particle data set (velocity moments and flux of electrons and ions, detection of heavy ions, flux of energetic neutral atoms) and the field data set (DC to low-frequency magnetic field at $128-\mathrm{Hz}$ sampling, spacecraft potential at $128-\mathrm{Hz}$ sampling, electric field at $128-\mathrm{Hz}$ sampling, strength of high-frequency waves in the magnetic field at $20-\mathrm{kHz}$ sampling and electric field at $100-\mathrm{kHz}$ sampling, and electron density and temperature evaluated from the wave spectrum). The reference parameters are defined in Table 4 in Kasaba et al. (2020). The on-board trigger-decision logic (referred to as the mission digital processor automatic trigger complex system, or the MATRIX system, in short) takes various combinations of up to four reference parameters to set the starting and stopping times. The H-mode retrieval is automatically activated by the trigger logic when the absolute or differential values of the reference parameters simultaneously exceed thresholds that are defined a priori in the parameter table. The score is evaluated on each triggered interval. The H-mode data with the highest score overwrite that with a lower score in the system data recorder. The automatic-triggering scheme can store a maximum of five events (there are five $\mathrm{H}$-mode partitions in the system data recorder). Tuning of the triggering logic (combinations of parameters and threshold definitions) will be exercised during the first year of Mio operation in the Hermean magnetosphere.

In the orbit phase near the perihelion (Fig. 12 bottom panel), the Mio spacecraft pericenter is located on the nightside of magnetosphere and the apo-center in the solar wind upstream of Mercury at a distance of about $6 R_{\mathrm{M}}$ (cf. the magnetopause distance is about $1.5 R_{\mathrm{M}}$ from the center of the planet). The perihelion phase is ideal for the Mio spacecraft to study the plasma dynamics in the inner heliosphere in great detail such as waves, turbulent fluctuations, discontinuities, and transient phenomena (coronal mass ejections, corotating interaction regions). Also, the coupling between the solar wind and Mercury's magnetosphere will be studied. The Mio spacecraft serves as a solar wind monitor and detects changes in the solar wind condition, while the MPO spacecraft observes the reaction of Mercury's magnetosphere to evaluate the arrival time and the consequences such as substormlike reconfiguration through the tail reconnection or wave activities.

The MGF magnetometer undergoes a check-out procedure twice a year during the cruise to Mercury to track the evolution of the instrument condition (e.g., temperature profile) at decreasing distances to the Sun. The interplanetary magnetic field will not be measured continuously.

\section{Summary and outlook}

The BepiColombo mission opens the door to comprehensively study Mercury's magnetosphere using two spacecraft and will answer the questions about the magnetospheric dynamics raised after the Mariner 10 and MESSENGER observations, in particular, magnetic reconnection, field-aligned currents, and ULF waves. The Mio magnetometer provides a continuous measurement of the magnetic field in the magnetosphere and solar wind ahead of the planet. Efforts in the development of data analysis techniques for multi-spacecraft 
(a) NEAR APOHELION

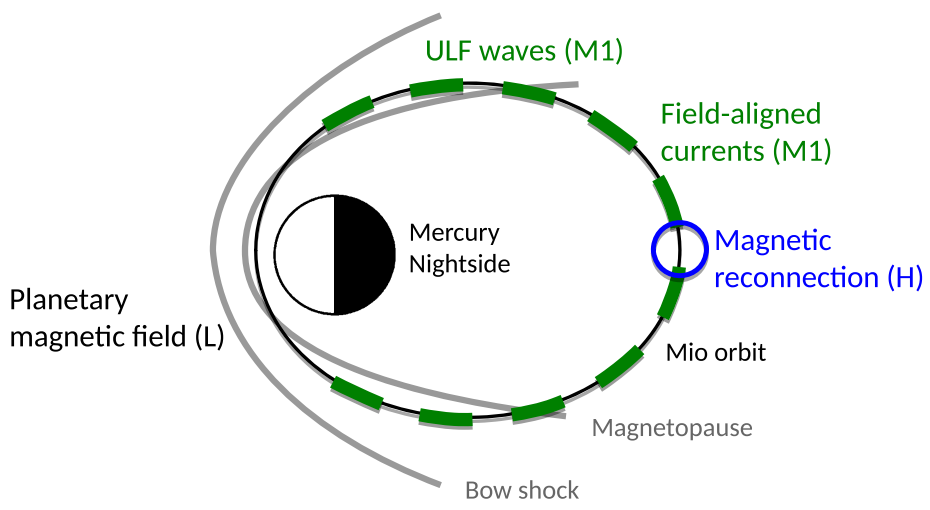

(b) NEAR PERIHELION

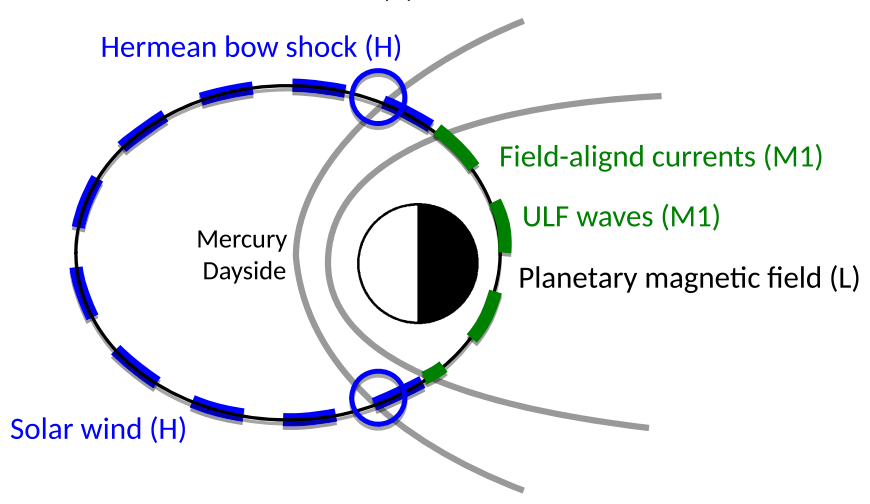

Fig. 12 MGF science targets and operation modes along the sketches of Mio orbits. A more precise calculations of the orbits are shown in Milillo et al. (2020)

data, modeling of the magnetosphere and each plasma process therein, extension of the theoretical studies, revisiting Mariner 10 and MESSENGER data, and close collaboration with the numerical simulations will continue prior to the arrival at Mercury.

Acknowledgements The Austrian team of the Mio magnetometer has financially been supported by the Austrian Space Applications Programme (ASAP) which is managed by the Austrian Research Promotion Agency (FFG). The work by Y. Narita was supported by ASAP/FFG project 865967 . The work by D. Heyner was supported by the German Ministerium für Wirtschaft und Energie and the German Zentrum für Luft- und Raumfahrt under contract 50 QW 1501.

Publisher's Note Springer Nature remains neutral with regard to jurisdictional claims in published maps and institutional affiliations.

Open Access This article is licensed under a Creative Commons Attribution 4.0 International License, which permits use, sharing, adaptation, distribution and reproduction in any medium or format, as long as you give appropriate credit to the original author(s) and the source, provide a link to the Creative Commons licence, and indicate if changes were made. The images or other third party material in this article are included in the article's Creative Commons licence, unless indicated otherwise in a credit line to the material. If material is not included in the article's Creative Commons licence and your intended use is not permitted 
by statutory regulation or exceeds the permitted use, you will need to obtain permission directly from the copyright holder. To view a copy of this licence, visit http://creativecommons.org/licenses/by/4.0/.

\section{References}

S.-I. Akasofu, The development of the auroral substorm. Planet. Space Sci. 12, 273-282 (1964). https:// doi.org/10.1016/0032-0633(64)90151-5

B.J. Anderson, M.H. Acuña, H. Korth, J.A. Slavin, H. Uno, C.L. Johnson, M.E. Purucker, S.C. Solomon, J.M. Raines, T.H. Zurbuchen, G. Gloecker, R.L. McNutt Jr., The magnetic field of Mercury. Space Sci. Rev. 152, 307-339 (2010). https://doi.org/10.1007/s11214-009-9544-3

B.J. Anderson, C.L. Johnson, H. Korth, M.E. Purucker, R.M. Winslow, J.A. Slavin, S.C. Solomon, R.L. McNutt Jr., J.M. Raines, T.H. Zurbuchen, The global magnetic field of Mercury from MESSENGER orbital observations. Science 333, 1859-1862 (2011). https://doi.org/10.1126/science.1211001

B.J. Anderson, C.L. Johnson, H. Korth, R.M. Winslow, J.E. Borovsky, M.E. Purucker, J.A. Slavin, S.C. Solomon, M.T. Zuber, R.L. McNutt Jr., Low-degree structure in Mercury's planetary magnetic field. J. Geophys. Res. 117, E00L12 (2012). https://doi.org/10.1029/2012JE004159

B.J. Anderson, C.L. Johnson, H. Korth, J.A. Slavin, R.M. Winslow, R.J. Phillips, R.L. McNutt, S.C. Solomon, Steady-state field-aligned currents at Mercury. Geophys. Res. Lett. 41, 7444-7452 (2014). https://doi.org/10.1002/2014GL061677

V. Angelopoulos, J.P. McFadden, D. Larson, C.W. Carlson, S.B. Mende, H. Frey, T. Phan, D.G. Sibeck, K.-H. Glassmeier, U. Auster, E. Donovan, I.R. Mann, I.J. Rae, C.T. Russell, A. Runov, X.-Z. Zhou, L. Kepko, Tail reconnection triggering substorm onset. Science 321, 931-935 (2008). https://doi.org/ 10.1126/science. 1160495

H.-U. Auster, A. Lichopoj, J. Rustenbach, H. Bitterlich, K.-H. Fornaçon, O. Hillenmaier, R. Krause, H.J. Schenk, V. Auster, Concept and first results of a digital fluxgate magnetometer. Meas. Sci. Technol. 5, 477-481 (1995). https://doi.org/10.1088/0957-0233/6/5/007

H.-U. Auster, I. Apathy, G. Berghofer, A. Remizov, R. Roll, K.-H. Fornaçon, K.-H. Glassmeier, G. Haerendel, I. Hejja, E. Kührt, W. Magnes, D. Moehlmann, U. Motschmann, I. Richter, H. Rosenbauer, C.T. Russell, J. Rustenbach, K. Sauer, K. Schwingenschuh, I. Szemerey, R. Waesch, ROMAP: Rosetta magnetometer and plasma monitor. Space Sci. Rev. 128, 221-240 (2007). https://doi.org/ 10.1007/s11214-006-9033-X

H.-U. Auster, K.-H. Glassmeier, W. Magnes, Ö. Aydogar, W. Baumjohann, D. Constantinescu, D. Fischer, K.-H. Fornaçon, E. Georgescu, P. Harvey, O. Hillenmaier, R. Kroth, M. Ludlam, Y. Narita, R. Nakamura, K. Okrafka, F. Plaschke, I. Richter, H. Schwarzl, B. Stoll, A. Valavanoglou, M. Wiedemann, The THEMIS fluxgate magnetometer. Space Sci. Rev. 141, 235-264 (2008). https://doi.org/ 10.1007/s11214-008-9365-9

A. Balogh, Mercury: the planet and its magnetosphere. Planet. Space Sci. 45, 1-2 (1997). https://doi.org/ 10.1016/S0032-0633(97)88333-X

A. Balogh, Planetary magnetic field measurements: missions and instrumentation. Space Sci. Rev. 152, 23-97 (2010). https://doi.org/10.1007/s11214-010-9643-1

W. Baumjohann, A. Matsuoka, K.-H. Glassmeier, C.T. Russell, T. Nagai, M. Hoshino, T. Nakagawa, A. Balogh, J.A. Slavin, R. Nakamura, W. Magnes, The magnetosphere of Mercury and its solar wind environment: open issues and scientific questions. Adv. Space Res. 38, 604-609 (2006). https://doi.org/ 10.1016/j.asr.2005.05.117

W. Baumjohann, A. Matsuoka, W. Magnes, K.-H. Glassmeier, R. Nakamura, R.H. Biernat, M. Delva, K. Schwingenschuh, T. Zhang, H.-U. Auster, K.-H. Fornaçon, I. Richter, A. Balogh, P. Cargill, C. Carr, M. Dougherty, T.S. Horbury, E.A. Lucek, F. Tohyama, T. Takahashi, M. Tanaka, T. Nagai, H. Tsunakawa, M. Matsuhima, H. Kawano, A. Yoshikawa, H. Shibuya, T. Nakagawa, M. Hoshino, Y. Tanaka, R. Kataoka, B.J. Anderson, C.T. Russell, U. Motschmann, M. Shinohara, Magnetic field investigation of Mercury's magnetosphere and the inner heliosphere by MMO/MGF. Planet. Space Sci. 58, 279-286 (2010). https://doi.org/10.1016/j.pss.2008.05.019

J. Benkhoff, J. van Castern, H. Hayakawa, M. Fujimoto, H. Laakso, M. Novara, P. Ferri, H.R. Middleton, R. Ziethe, BepiColombo-comprehensive exploration of Mercury: mission overview and science goals. Planet. Space Sci. 58, 2-20 (2010). https://doi.org/10.1016/j.pss.2009.09.020

S.A. Boardsen, J.A. Slavin, Search for pick-up ion generated $\mathrm{Na}^{+}$cyclotronwaves at Mercury. Geophys. Res. Lett. 34, L22106 (2007). https://doi.org/10.1029/2007GL031504

S.A. Boardsen, T. Sundberg, J.A. Slavin, B.J. Anderson, H. Korth, S.C. Solomon, L.G. Blomberg, Observations of Kelvin-Helmholtz waves along the dusk-side boundary of Mercury's magneto- 
sphere during MESSENGER's third flyby. Geophys. Res. Lett. 37, L12101 (2010). https://doi.org/ 10.1029/2010GL043606

S.A. Boardsen, J.A. Slavin, B.J. Anderson, H. Korth, D. Schriver, S.C. Solomon, Survey of coherent $\sim 1$ $\mathrm{Hz}$ waves in Mercury's inner magnetosphere from MESSENGER observations. J. Geophys. Res. 117, A00M05 (2012). https://doi.org/10.1029/2012JA017822

C.R. Clauer, R.L. McPherron, Mapping of local time, universal time development of magnetosphere substorms using midlatitude magnetic observations. J. Geophys. Res. 79, 2812-2820 (1974). https://doi.org/ 10.1029/JA079i019p02811

S.W.H. Cowley, Magnetosphere-ionosphere interactions: A tutorial review, in Magnetospheric Current Systems, ed. by S. Ohtani, R. Fujii, M. Hesse, R.L. Lysak. Geophys. Monogr. Ser., vol. 118 (American Geophysical Union, Washington, 2000), pp. 91-106. https://doi.org/10.1029/GM118p0091

D.C. Delcourt, T.E. Moore, M.-C.H. Fok, Ion dynamics during compression of Mercury's magnetosphere. Ann. Geophys. 28, 1467-1474 (2010). https://doi.org/10.5194/angeo-28-1467-2010

G.A. DiBraccio, J.A. Slavin, S.A. Boardsen, B.J. Anderson, H. Korth, T.H. Zurbuchen, J.M. Raines, D.N. Baker, R.L. McNutt, S.C. Solomon, MESSENGER observations of magnetopause structure and dynamics at Mercury. J. Geophys. Res. Space Phys. 118, 997-1008 (2013). https://doi.org/10.1002/ jgra.50123

W. Exner, D. Heyner, L. Liuzzo, U. Motschmann, D. Shiota, K. Kusano, T. Shibayama, Coronal mass ejection hits Mercury: A.I.K.E.F. hybrid-code results compared to MESSENGER data. Planet. Space Sci. 153, 89-99 (2018). https://doi.org/10.1016/j.pss.2017.12.016

W. Exner, S. Simon, D. Heyner, U. Motschmann, Influence of Mercury's exosphere on the structure of the magnetosphere. J. Geophys. Res. Space Phys. 125, e2019JA027691 (2020). https://doi.org/ 10.1029/2019JA027691

D.H. Fairfield, K.W. Behannon, Bow shock and magnetosheath waves at Mercury. J. Geophys. Res. 81, 3897-3906 (1976). https://doi.org/10.1029/JA081i022p03897

H. Fukunishi, R. Fujii, S. Kokubun, K. Hayashi, F. Tohyama, Y. Tonegawa, S. Okano, M. Sugiura, K. Yumoto, I. Aoyama, T. Sakurai, T. Saito, T. Iijima, A. Nishida, M. Natori, Magnetic field observations on the AKEBONO (EXOS-D) satellite. J. Geomagn. Geoelectr. 42, 385-409 (1990). https://doi.org/ 10.5636/jgg.42.385

E. Georgescu, H.U. Auster, T. Takada, J. Gloag, H. Eichelberger, K.-H. Fornaçon, P. Brown, C.M. Carr, T.L. Zhang, Modified gradiometer technique applied to Double Star (TC-1). Adv. Space Res. 41, 1579-1584 (2008). https://doi.org/10.1016/j.asr.2008.01.014

D.J. Gershman, J.M. Raines, J.A. Slavin, T.H. Zurbuchen, T. Sundberg, S.A. Boardsen, B.J. Anderson, H. Korth, S.C. Solomon, MESSENGER observations of multiscale Kelvin-Helmholtz vortices at Mercury. J. Geophys. Res. Space Phys. 120, 4354-4368 (2015). https://doi.org/10.1002/2014JA020903

K.-H. Glassmeier, The Hermean magnetosphere and its ionosphere-magnetosphere coupling. Planet. Space Sci. 45, 119-125 (1997). https://doi.org/10.1016/S0032-0633(96)00095-5

K.-H. Glassmeier, Currents in Mercury's magnetosphere, in Magnetospheric Current Systems, ed. by E.S.I. Ohtani, R. Fujii, M. Hesse, R.L. Lysak. Geophysical Monograph, vol. 118 (2000), pp. 371-380. https://doi.org/10.1029/GM118p0371

K.-H. Glassmeier, P.N. Mager, D.Y. Klimushkin, Concerning ULF pulsations in Mercury's magnetosphere. Geophys. Res. Lett. 30, 1928 (2003). https://doi.org/10.1029/2003GL017175.

K.-H. Glassmeier, D. Klimushkin, C. Othmer, P. Mager, ULF waves at Mercury: Earth, the giants, and their little brother compared. Adv. Space Res. 33, 1875-1883 (2004). https://doi.org/10.1016/ j.asr.2003.04.047

K.-H. Glassmeier, J. Espley, ULF waves in planetary magnetospheres, in Magnetospheric ULF Waves: Synthesis and New Directions, ed. by E.K. Takahashi, P.J. Chi, R.E. Denton, R.L. Lysak (American Geophysical, Union, 2006), pp. 341-349. https://doi.org/10.1029/169GM22

K.-H. Glassmeier, H.-U. Auster, U. Motschmann, A feedback dynamo generating Mercury's magnetic field. Geophys. Res. Lett. 34, L22201 (2007). https://doi.org/10.1029/2007GL031662

K.-H. Glassmeier, H.-U. Auster, D. Heyner, K. Okrafka, C. Carr, G. Berghofer, B.J. Anderson, A. Balogh, W. Baumjohann, P. Cargill, U. Christensen, M. Delva, M. Dougherty, K.-H. Fornaçon, T.S. Horbury, E.A. Lucek, W. Magnes, M. Mandea, A. Matsuoka, M. Matsushima, U. Motschmann, R. Nakamura, Y. Narita, H. O’Brien, I. Richter, K. Schwingenschuh, H. Shibuya, J.A. Slavin, C. Sotin, B. Stoll, H.T. sunakawa, S. Vennerstrom, J. Vogt, T. Zhang, The fluxgate magnetometer of the BepiColombo Mercury Planetary Orbiter. Planet. Space Sci. 58, 287-299 (2010). https://doi.org/10.1016/j.pss.2008.06.018

J. Grosser, K.-H. Glassmeier, A. Stadelmann, Induced magnetic field effects at planet Mercury. Planet. Space Sci. 52, 1251-1260 (2004). https://doi.org/10.1016/j.pss.2004.08.005

P.C. Hedgecock, A correlation technique for magnetometer zero level determination. Space Sci. Instrum. 1, 83-90 (1975) 
D. Heyner, J. Wicht, N. Gómez-Pŕez, D. Schmitt, H.-U. Auster, K.-H. Glassmeier, Evidence from numerical experiments for a feedback dynamo generating Mercury's magnetic field. Science 334, 1690-1693 (2011). https://doi.org/10.1126/science. 1207290

D. Heyner, C. Nabert, E. Liebert, K.-H. Glassmeier, Concerning reconnection-induction balance at the magnetopause of Mercury. J. Geophys. Res. Space Phys. 121, 2935-2961 (2016). https://doi.org/10.1002/ 2015JA021484

D. Heyner, H.-U. Auster, K.-H. Fornaçon, I. Richter, J. Mieth, P. Kolhey, W. Magnes, G. Berghofer, D. Fischer, F. Plaschke, C.M. Carr, B.J. Anderson, A. Balogh, W. Baumjohann, M. Delva, M. Dougherty, T.S. Horbury, B. Langlais, M. Mandea, A. Masters, A. Matsuoka, M. Matsushima, U. Motschmann, R. Nakamura, Y. Narita, H. Shibuya, J. Slavin, H. Tsunakawa, S. Vennerström, J. Vogt, M.J. Volwerk, Wicht, T. Zhang, K.-H. Glassmeier, The BepiColombo Planetary Magnetometer En-Route to Mercury: what can we learn from the planetary magnetic field? Space Sci. Rev. (2020), this issue

J.V. Hollweg, P.A. Isenberg, Generation of the fast solar wind: a review with emphasis on the resonant cyclotron interaction. J. Geophys. Res. 107, 1147 (2002). https://doi.org/10.1029/2001JA000270

M. Hoshino, N. Shimada, Nonthermal electrons at high Mach number shocks: electron shock surfing acceleration. Astrophys. J. 572, 880-887 (2002). https://doi.org/10.1086/340454

T. Iijima, T.A. Potemra, Field-aligned currents in the dayside cusp observed by Triad. J. Geophys. Res. 81, 5971-5979 (1976). https://doi.org/10.1029/JA081i034p05971

M. Itonaga, A. Yoshikawa, S. Fujita, A wave equation describing the generation of field-aligned current in the magnetosphere. Earth Planets Space 52, 503-507 (2000). https://doi.org/10.1186/BF03351654

M.K. James, E.J. Bunce, T.K. Yeoman, S.M. Imber, H. Korth, A statistical survey of ultra-low-frequency wave power and polarization in the Hermean magnetosphere. J. Geophys. Res. Space Phys. 121, 87558772 (2016). https://doi.org/10.1002/2016JA023103

C.L. Johnson, M.E. Purucker, H. Korth, B.J. Anderson, R.M. Winslow, M.M.H. Al Asad, J.A. Slavin, I.I. Alexeev, R.J. Phillips, M.T. Zuber, S.C. Solomon, MESSENGER observations of Mercury's magnetic field structure. J. Geophys. Res. 117, E00L14 (2012). https://doi.org/10.1029/2012JE004217

C.L. Johnson, R.J. Phillips, M.E. Purucker, B.J. Anderson, P.K. Byrne, B.W. Denevi, J.M. Feinberg, S.A. Hauck II., J.W. Head III., H. Korth, P.B. James, E. Mazarico, G.A. Neumann, L.C. Philpott, M.A. Siegler, N.A. Tsyganenko, S.C. Solomon, Low-altitude magnetic field measurements by MESSENGER reveal Mercury's ancient crustal field. Science 348, 892-895 (2015). https://doi.org/10.1126/ science.aaa8720

C.L. Johnson, L.C. Philpott, B.J. Anderson, H. Korth, S.A. Hauck II., D. Heyner, R.J. Phillips, R.M. Winslow, S.C. Solomon, MESSENGER observations of induced magneticfields in Mercury's core. Geophys. Res. Lett. 43, 2436-2444 (2016). https://doi.org/10.1002/2015GL067370

J.R. Kan, T.A. Potemra, S. Kokubun, T. Iijima, Magnetospheric Substorms. Geophysical Monograph Series, vol. 64 (American Geophysical, Union, 1991), p. 488. https://doi.org/10.1029/GM064. Washington

T. Karlsson, E. Liljebad, A. Kullen, J.M. Raines, J.A. Slavin, T. Sundberg, Isolated magnetic field structures in Mercury's magnetosheath as possible analogues for terrestrial magnetosheath plasmoids and jets. Planet. Space Sci. 129, 61-73 (2016). https://doi.org/10.1016/j.pss.2016.06.002

Y. Kasaba, T. Takashima, S. Matsuda, S. Eguchi, M. Endo, T. Miyabara, M. Taeda, Y. Kuroda, Y. Kasahara, T. Imachi, H. Kojima, S. Yagitani, M. Moncuquet, J.-E. Wahlund, A. Kumamoto, A. Matsuoka, W. Baumjohann, S. Yokota, K. Asamura, Y. Saito, D. Delcourt, M. Hirahara, S. Barabash, N. Andre, M. Kobayashi, I. Yoshikawa, G. Murakami, H. Hayakawa, Mission data processor aboard the BepiColombo Mio spacecraft, design and scientific operation concept. Space Sci. Rev. 216, 34 (2020). https://doi.org/10.1007/s11214-020-00658-x

E.L. Kepko, K.K. Khurana, M.G. Kivelson, R.C. Elphic, C.T. Russell, Accurate determination of magnetic field gradients from four point vector measurements. I. Use of natural constraints on vector data obtained from a single spinning spacecraft. IEEE Trans. Magn. 32, 377-385 (1996). https://doi.org/ 10.1109/20.486522

L. Kepko, R.L. McPherron, O. Amm, S. Apatenkov, W. Baumjohann, J. Birn, M. Lester, R. Nakamura, T.I. Pulkkinen, V. Sergeev, Substorm current wedge revisited. Space Sci. Rev. 190, 1-46 (2015). https://doi.org/10.1007/s11214-014-0124-9

E.-H. Kim, J.R. Johnson, D.-H. Lee, Y.S. Pyo, Field-line resonance structures in Mercury's multi-ion magnetosphere. Earth Planets Space 65, 447-451 (2013). https://doi.org/10.5047/eps.2012.08.004

S. Kokubun, T. Yamamoto, M.H. Acuna, K. Hayashi, K. Shiokawa, H. Kawano, The GEOTAIL magnetic field experiment. J. Geomagn. Geoelectr. 46, 7-21 (1994). https://doi.org/10.5636/jgg.46.7

H. Korth, N.A. Tsyganenko, C.L. Johnson, L.C. Philpott, B.J. Anderson, M.M. Al Asad, S.C. Solomon, R.L. McNutt Jr., Modular model for Mercury's magnetospheric magnetic field confined within the average observed magnetopause. J. Geophys. Res. Space Phys. 120, 4503-4518 (2015). https://doi.org/ 10.1002/2015JA021022 
H.K. Leinweber, C.T. Russell, K. Torkar, T.L. Zhang, V.A. Angelopoulos, An advanced approach to finding magnetometer zero levels in the interplanetary magnetic field. Meas. Sci. Technol. 19, 055104 (2008). https://doi.org/10.1088/0957-0233/19/5/055104

E. Liljeblad, T. Sundberg, T. Karlsson, A. Kullen, Statistical investigation of Kelvin-Helmholtz waves at the magnetopause of Mercury. J. Geophys. Res. Space Phys. 119, 9670-9683 (2014). https://doi.org/ 10.1002/2014JA020614

E. Liljeblad, T. Karlsson, T. Sundberg, A. Kullen, Observations of magnetospheric ULF waves in connection with the Kelvin-Helmholtz instability at Mercury. J. Geophys. Res. Space Phys. 121, 8576-8588 (2016). https://doi.org/10.1002/2016JA023015

S.T. Lindsay, M.K. James, E.J. Bunce, S.M. Imber, H. Korth, A. Martindale, T.K. Yeoman, MESSENGER X-ray observations of magnetosphere-surface interaction on the nightside of Mercury. Planet. Space Sci. 125, 72-79 (2016). https://doi.org/10.1016/j.pss.2016.03.005

C. Lhotka, Y. Narita, Kinematic models of the interplanetary magnetic field. Ann. Geophys. 37, 299-314 (2019). https://doi.org/10.5194/angeo-37-299-2019

A. Matsuoka, M. Shinohara, Y. Tanaka, A. Fujimoto, K. Iguchi, Development of fluxgate magnetometers and applications to the space science missions, in An Introduction to Space Instrumentation, ed. by E.K.-I. Oyama, C.Z. Cheng (Terra Scientific Publishing Company, Tokyo, 2013), pp. 217-225. https://doi.org/10.5047/aisi.021

A. Matsuoka, M. Teramoto, R. Nomura, In-orbit alignment analysis of the magnetometer sensor on the Arase (ERG) satellite, JAXA Research and Development Report, JAXA-RR-18-005E, pp. 17-22 (2019). https://doi.org/10.20637/JAXA-RR-18-005E/0003

A. Milillo, M. Fujimoto, G. Murakami, J. Benkhoff, J. Zender, S. Aizawa, M. Dósa, L. Griton, D. Heyner, G. Ho, S.M. Imber, X. Jia, T. Karlsson, R.M. Killen, M. Laurenza, S.T. Lindsay, S. McKenna-Lawlor, A. Mura, J.M. Raines, D.A. Rothery, N. André, W. Baumjohann, A. Berezhnoy, P.A. Bourdin, E.J. Bunce, F. Califano, J. Deca, S. de la Fuente, C. Dong, C. Grava, S. Fatemi, P. Henri, S.L. Ivanovski, B.V. Jackson, M. James, E. Kallio, Y. Kasaba, E. Kilpua, M. Kobayashi, B. Langlais, F. Leblanc, C. Lhotka, V. Mangano, A. Martindale, S. Massetti, A. Masters, M. Morooka, Y. Narita, J.S. Oliveira, D. Odstrcil, S. Orsini, M.G. Pelizzo, C. Plainaki, F. Plaschke, F. Sahraoui, K. Seki, J.A. Slavin, R. Vainio, P. Wurz, S. Barabash, C.M. Carr, D. Delcourt, K.-H. Glassmeier, M. Grande, M. Hirahara, J. Huovelin, O. Korablev, H. Kojima, H. Lichtenegger, S. Livi, A. Matsuoka, R. Moissl, M. Moncuquet, K. Muinonen, E. Quèmerais, Y. Saito, S. Yagitani, I. Yoshikawa, J.-E. Wahlund, Investigating Mercury's environment with the two-spacecraft BepiColombo mission. Space Sci. Rev. 216, 93 (2020). https://doi.org/ 10.1007/s11214-020-00712-8

J. Müller, S. Simon, Y.-C. Wang, U. Motschmann, D. Heyner, J. Schüle, W.-H. Ip, G. Kleindienst, G.J. Pringle, Origin of Mercury's double magnetopause: 3D hybrid simulation study with A.I.K.E.F. Icarus 218, 666-687 (2012). https://doi.org/10.1016/j.icarus.2011.12.028

G. Murakami, H. Hayakawa, H. Ogawa, S. Matsuda, T. Seki, Y. Kasaba, Y. Saito, I. Yoshikawa, M. Kobayashi, W. Baumjohann, A. Matsuoka, H. Kojima, S. Yagitani, M. Moncuquet, J.E. Wahlund, D. Delcourt, M. Hirahara, S. Barabash, O. Korablev, M. Fujimoto, Mio-first comprehensive exploration of Mercury's space environment: mission overview. Space Sci. Rev. 216, 113 (2020). https://doi.org/ 10.1007/s11214-020-00733-3

N.F. Ness, K.W. Behannon, R.P. Lepping, K.H. Schatten, Use of two magnetometers for magnetic field measurements on a spacecraft. J. Geophys. Res. 76, 3565-3573 (1971). https://doi.org/10.1029/ JA076i016p03564

N.F. Ness, K.W. Behannon, R.P. Lepping, Y.C. Whang, K.H. Schatten, Magnetic field observations near Mercury: preliminary results from Mariner 10. Science 185, 151-160 (1974). https://doi.org/10.1126/ science.185.4146.151

N.F. Ness, K.W. Behannon, R.P. Lepping, Y.C. Whang, The magnetic field of Mercury, 1. J. Geophys. Res. 80, 2708-2716 (1975). https://doi.org/10.1029/JA080i019p02708

J.S. Oliveira, L.L. Hood, B. Langlais, Constraining the early history of Mercury and its core dynamo by studying the crustal magnetic field. J. Geophys. Res., Planets 124, 2382-2396 (2019). https:// doi.org/10.1029/2019JE005938

C. Othmer, K.-H. Glassmeier, R. Cramm, Concerning field line resonances in Mercury's magnetosphere. J. Geophys. Res. 104, 10369-10378 (1999). https://doi.org/10.1029/1999JA900009

J. Paral, R. Rankin, Dawn-dusk asymmetry in the Kelvin-Helmholtz instability at Mercury. Nat. Commun. 4, 1645 (2013). https://doi.org/10.1038/ncomms2676

S. Perri, V. Carbone, P. Veltri, Where does fluid-like turbulence break down in the solar wind? Astrophys. J. Lett. 725, L52-L55 (2010). https://doi.org/10.1088/2041-8205/725/1/L52

S. Perri, V. Carbone, A. Vecchio, R. Bruno, H. Korth, T.H. Zurbuchen, L. Sorriso-Valvo, Phasesynchronization, energy cascade, and intermittency in solar-wind turbulence. Phys. Rev. Lett. 109, 245004 (2012). https://doi.org/10.1103/PhysRevLett.109.245004 
F. Plaschke, Y. Narita, On determining fluxgate magnetometer spin axis offsets from mirror mode observations. Ann. Geophys. 34, 759-766 (2016). https://doi.org/10.5194/angeo-34-759-2016

F. Plaschke, C. Goetz, M. Volwerk, I. Richter, D. Frühauff, Y. Narita, K.-H. Glassmeier, M.K. Dougherty, Fluxgate magnetometer offset vector determination by the $3 \mathrm{D}$ mirror mode method. Mon. Not. R. Astron. Soc. 469, S675-S684 (2017). https://doi.org/10.1093/mnras/stx2532

F. Plaschke, H.-U. Auster, D. Fischer, K.-H. Fornaçon, W. Magnes, I. Richter, D. Constantinescu, Y. Narita, Advanced calibration of magnetometers on spin-stabilized spacecraft based on parameter decoupling. Geosci. Instrum. Method. Data Syst. 8, 63-76 (2019). https://doi.org/10.5194/gi-8-63-2019

F. Plaschke, How many solar wind data are sufficient for accurate fluxgate magnetometer offset determinations? Geosci. Instrum. Method. Data Syst. 8, 285-291 (2019). https://doi.org/10.5194/gi-8-285-2019

F. Primdahl, The fluxgate magnetometer. J. Phys. E, Sci. Instrum. 12, 241-253 (1979). https://doi.org/ 10.1088/0022-3735/12/4/001

P. Ritter, H. Lühr, Near-Earth magnetic signature of magnetospheric substorms and suggestions for a new substorm current model. Ann. Geophys. 26, 2781-2793 (2008). https://doi.org/10.5194/ angeo-26-2781-2008

C.T. Russell, ULF waves in the Mercury magnetosphere. Geophys. Res. Lett. 16, 1253-1256 (1989). https://doi.org/10.1029/GL016i011p01253

C.T. Russell, B.J. Anderson, W. Baumjohann, K.R. Bromund, D. Dearborn, D. Fischer, G. Le, H.K. Leinweber, D. Leneman, W. Magnes, J.D. Means, M.B. Moldwin, R. Nakamura, D. Pierce, F. Plaschke, K.M. Rowe, J.A. Slavin, R.J. Strangeway, R. Torbert, C. Hagen, I. Jernej, A. Valavanoglou, I. Richter, The magnetospheric multiscale magnetometers. Space Sci. Rev. 199, 189-256 (2016). https://doi.org/10.1007/s11214-014-0057-3

D. Schmid, F. Plaschke, Y. Narita, D. Heyner, J.Z.D. Mieth, B.J. Anderson, M. Volwerk, A. Matsuoka, W. Baumjohann, Magnetometer in-flight offset accuracy for the BepiColombo spacecraft. Ann. Geophys. 38, 823-832 (2020). https://doi.org/10.5194/angeo-38-823-2020

G.L. Siscoe, N.F. Ness, C.M. Yeates, Substorms on Mercury? J. Geophys. Res. 80, 4359-4363 (1975). https://doi.org/10.1029/JA080i031p04359

J.A. Slavin, C.J. Owen, J.E.P. Connerney, S.P. Christon, Mariner 10 observations of field-aligned currents at Mercury. Planet. Space Sci. 45, 133-141 (1997). https://doi.org/10.1016/S0032-0633(96)00104-3

J.A. Slavin, M.H. Acuña, B.J. Anderson, D.N. Baker, M. Benna, S.A. Boardsen, G. Gloeckler, R.E. Gold, G.C. Ho, H. Korth, S.M. Krimigis, R.L. McNutt, J.M. Raines, M. Sarantos, D. Schriver, S.C. Solomon, P. Trávníček, T.H. Zurbuchen, MESSENGER observations of magnetic reconnection in Mercury's magnetosphere. Science 324, 606-610 (2009). https://doi.org/10.1126/science.1172011

J.A. Slavin, B.J. Anderson, T.H. Zurbuchen, D.N. Baker, S.M. Krimigis, M.H. Acuña, M. Benna, S.A. Boardsen, G. Gloeckler, R.E. Gold, G.C. Ho, H. Korth, R.L. McNutt Jr., J.M. Raines, M. Sarantos, D. Schriver, S.C. Solomon, P. Trávníček, MESSENGER observations of Mercury’s magnetosphere during northward IMF. Geophys. Res. Lett. 36, L02101 (2009b). https://doi.org/10.1029/2008GL036158

J.A. Slavin, S.M. Imber, S.A. Boardsen, G.A. DiBraccio, T. Sundberg, M. Sarantos, T. Nieves-Chinchilla, A. Szabo, B.J. Anderson, H. Korth, T.H. Zurbuchen, J.M. Raines, C.L. Johnson, R.M. Winslow, R.M. Killen, R.L. McNutt Jr., S.C. Solomon, MESSENGER observations of a flux-transfer-event shower at Mercury. J. Geophys. Res. 117, A00M06 (2012). https://doi.org/10.1029/2012JA017926

J.A. Slavin, G.A. DiBraccio, D.J. Gershman, S.M. Imber, G.K. Poh, J.M. Raines, T.H. Zurbuchen, X. Jia, D.N. Baker, K.-H. Glassmeier, S.A. Livi, S.A. Boardsen, T.A. Cassidy, M. Sarantos, T. Sundberg, A. Masters, C.L. Johnson, R.M. Winslow, B.J. Anderson, H. Korth, R.L. McNutt Jr., S.C. Solomon, MESSENGER observations of Mercury's dayside magnetosphere under extreme solar wind conditions. J. Geophys. Res. Space Phys. 119, 8087-8116 (2014). https://doi.org/10.1002/2014JA020319

J.A. Slavin, H.R. Middleton, J.M. Raines, X. Jia, J. Zhong, W.-J. Sun, S. Livi, S.M. Imber, G.-K. Poh, M. Akhavan-Tafti, J.M. Jasinski, G.A. DiBraccio, C. Dong, R.M. Dewey, M.L. Mays, MESSENGER observations of disappearing dayside magnetosphere events at Mercury. J. Geophys. Res. Space Phys. 124, 6613-6635 (2019). https://doi.org/10.1029/2019JA026892

S.C. Solomon, R.L. McNutt Jr., R.E. Gold, D.L. Domingue, MESSENGER mission overview. Space Sci. Rev. 131, 3-39 (2007). https://doi.org/10.1007/s11214-007-9247-6

D.J. Southwood, M. Kivelson, An approximate description of field-aligned currents in a planetary magnetic field. J. Geophys. Res. 96, 67-75 (1991). https://doi.org/10.1029/90JA01806

T. Sundberg, S.A. Boardsen, J.A. Slavin, L.G. Blomberg, J.A. Cumnock, S.C. Solomon, B.J. Anderson, H. Korth, Reconstruction of propagating Kelvin-Helmholtz vortices at Mercury's magnetopause. Planet. Space Sci. 59, 2051-2057 (2011). https://doi.org/10.1016/j.pss.2011.05.008

T. Sundberg, J.A. Slavin, S.A. Boardsen, B.J. Anderson, H. Korth, G.C. Ho, D. Schriver, V.M. Uritsky, T.H. Zurbuchen, J.M. Raines, D.N. Baker, S.M. Krimigis, R.L. McNutt Jr., S.C. Solomon, MESSENGER observations of dipolarization events in Mercury's magnetotail. J. Geophys. Res. 117, A00M03 (2012a). https://doi.org/10.1029/2012JA017756 
T. Sundberg, S.A. Boardsen, J.A. Slavin, B.J. Anderson, H. Korth, T.H. Zurbuchen, J.M. Raines, S.C. Solomon, MESSENGER orbital observations of large-amplitude Kelvin-Helmholtz waves at Mercury's magnetopause. J. Geophys. Res. 117, A04216 (2012b). https://doi.org/10.1029/2011JA017268

T. Sundberg, S.A. Boardsen, J.A. Slavin, V.M. Uritsky, B.J. Anderson, H. Korth, D.J. Gershman, J.M. Raines, T.H. Zurbuchen, S.C. Solomon, Cyclic reformation of a quasi-parallel bow shock at Mercury: MESSENGER observations. J. Geophys. Res. 118, 6457-6464 (2013). https://doi.org/10.1002/jgra.50602

T. Sundberg, S.A. Boardsen, D. Burgess, J.A. Slavin, Coherent wave activity in Mercury's magnetosheath. J. Geophys. Res. Space Phys. 120, 7342-7356 (2015). https://doi.org/10.1002/2015JA021499

T.K. Suzuki, On the heating of the solar corona and the acceleration of the low-speed solar wind by acoustic waves generated in the corona. Astrophys. J. 578, 598-609 (2002). https://doi.org/10.1086/342347

V.M. Uritsky, J.A. Slavin, G.V. Khazanov, E.F. Donovan, S.A. Boardsen, B.J. Anderson, H. Korth, Kineticscale magnetic turbulence and finite Larmor radius effects at Mercury. J. Geophys. Res. 116, A09236 (2011). https://doi.org/10.1029/2011JA016744

S. Vennerstrøm, T. Moretto, N. Olsen, E. Friis-Christensen, A.M. Stampe, J.F. Watermann, Field-aligned currents in the dayside cusp and polar cap region during northward IMF. J. Geophys. Res. 107, SMP 18 (2002). https://doi.org/10.1029/2001JA009162

J. Wicht, D. Heyner, Mercury's magnetic field in the MESSENGER era, in Planetary Geodesy and Remote Sensing, vol. 10, ed. by E.S. Jin Chap (CRC Press, Boca Raton, 2014), pp. 223-262

T. Yamamoto, A. Matsuoka, PLANET-B magnetic fields investigation. Earth Planets Space 50, 189-194 (1998). https://doi.org/10.1186/BF03352102

L.J. Zanetti, T.A. Potemra, P.F. Bythrow, T. Iijima, W. Baumjohann, Ionospheric and Birkeland current distributions for northward interplanetary magnetic field - inferred polar convection. J. Geophys. Res. 89, 7453-7458 (1984). https://doi.org/10.1029/JA089iA09p07453

L. Zelenyi, M. Oka, M. Fujimoto, D. Delcourt, W. Baumjohann, Particle acceleration in Mercury's magnetosphere. Space Sci. Rev. 132, 593-609 (2007). https://doi.org/10.1007/s11214-007-9169-3

T.L. Zhang, W. Baumjohann, M. Delva, H.-U. Auster, A. Balogh, C.T. Russell, S. Barabash, M. Balikhin, G. Berghofer, H.K. Biernat, H. Lammer, H. Lichtenegger, W. Magnes, R. Nakamura, T. Penz, K. Schwingenschuh, Z. Vörös, W. Zambelli, K.-H. Fornaçon, K.-H. Glassmeier, I. Richter, C. Carr, K. Kudela, J.K. Shi, H. Zhao, U. Motschmann, J.-P. Lebreton, Magnetic field investigation of the Venus plasma environment: expected new results from Venus Express. Planet. Space Sci. 54, 1336-1343 (2006). https://doi.org/10.1016/j.pss.2006.04.018

T.L. Zhang, M. Delva, W. Baumjohann, H.-U. Auster, C. Carr, C.T. Russell, S. Barabash, M. Balikhin, K. Kudela, G. Berghofer, H.K. Biernat, H. Lammer, H. Lichtenegger, W. Magnes, R. Nakamura, K. Schwingenschuh, M. Volwerk, Z. Vörös, M. Zambelli, K.-H. Fornaçon, K.-H. Glassmeier, I. Richter, A. Balogh, H. Schwarzl, S.A. Pope, J.K. Shi, C. Wang, U. Motschmann, J.-P. Lebreton, Little or no solar wind enters Venus' atmosphere at solar minimum. Nature 450, 654-656 (2007). https://doi.org/ 10.1038/nature06026

J. Zhong, W.X. Wan, J.A. Slavin, Y. Wei, R.L. Lin, L.H. Chai, J.M. Raines, Z.J. Rong, X.H. Han, Mercury's three-dimensional asymmetric magnetopause. J. Geophys. Res. 120, 7658-7671 (2015). https://doi.org/ 10.1002/2015JA02142 